\title{
LA COLEGIATA DE SANTA MARÍA LA REAL DE XUNQUEIRA DE AMBÍA: LA RECUPERACIÓN DE SU PAZO PRIORAL*
}

\section{THE COLLEGIATE CHURCH OF SANTA MARIA THE XUNQUEIRA DE AMBIA'S LA REAL: THE RECOVERY OF HIS COUNTRY HOUSE PRIORAL.}

\author{
NIEVES AMADO ROLÁN ${ }^{1}$, \\ REBECA BLANCO-ROTEA ${ }^{2}$ Y SONIA GARCÍA RODRÍGUEZ ${ }^{2}$
}

\begin{abstract}
Resumen
Se presentan los resultados de los trabajos realizados en el Pazo Prioral de la Colegiata de Santa María de Xunqueira de Ambía con motivo de su reciente restauración. Los estudios llevados a cabo se basaron en el análisis de la documentación histórica y bibliográfica, el control arqueológico de la remoción de tierras y la lectura estratigráfica de alzados. A través de la información obtenida se ha podido recuperar la evolución constructiva del edificio, reinterpretar su funcionalidad y abrir nuevas vías de estudio sobre la interpretación de su evolución espacial y funcional, así como apuntar algunos aspectos sobre las marcas epigráficas documentadas.
\end{abstract}

\section{Palabras clave}

Rehabilitación Arquitectónica. Arqueología de la Arquitectura. Lectura Estratigráfica de Alzados. Análisis Histórico. Control Arqueológico. Arquitectura Monástica.

\begin{abstract}
The results of work carried out at the Priory of the Collegiate Church of Santa María in Xunqueira de Ambía are presented, following its recent restoration. The studies carried out were based on analysing historical and bibliographic documentation, archaeological control of earthmoving work, and the stratigraphic reading of elevations. Based on this information, it has been possible to define the constructional evolution of the building, reinterpret its function and open new inroads into explaining its spatial and functional evolution, as well as to describe a series of features relating to the inscriptions documented in the building.
\end{abstract}

\section{Keywords}

Architectural rehabilitation, Archaeology of Architecture, Stratigraphic Reading of Elevations, Historical Analysis, Archaeological Control, Monastic Architecture.

\footnotetext{
* Entregado en la Secretaría de Cuadernos de Estudios Gallegos el 19 de febrero de 2008.

${ }^{1}$ Arqueóloga, profesional liberal.

${ }^{2}$ Arqueóloga, miembro del Laboratorio de Arqueoloxía da Paisaxe, IEGPS, CSIC.
} 


\section{INTRODUCCIÓN}

El presente texto recoge los resultados de los distintos trabajos arqueológicos realizados en el año 2005 en el edificio denominado Pazo Prioral de la Colegiata de Santa María la Real de Xunqueira de Ambía (Xunqueira de Ambía, Ourense).
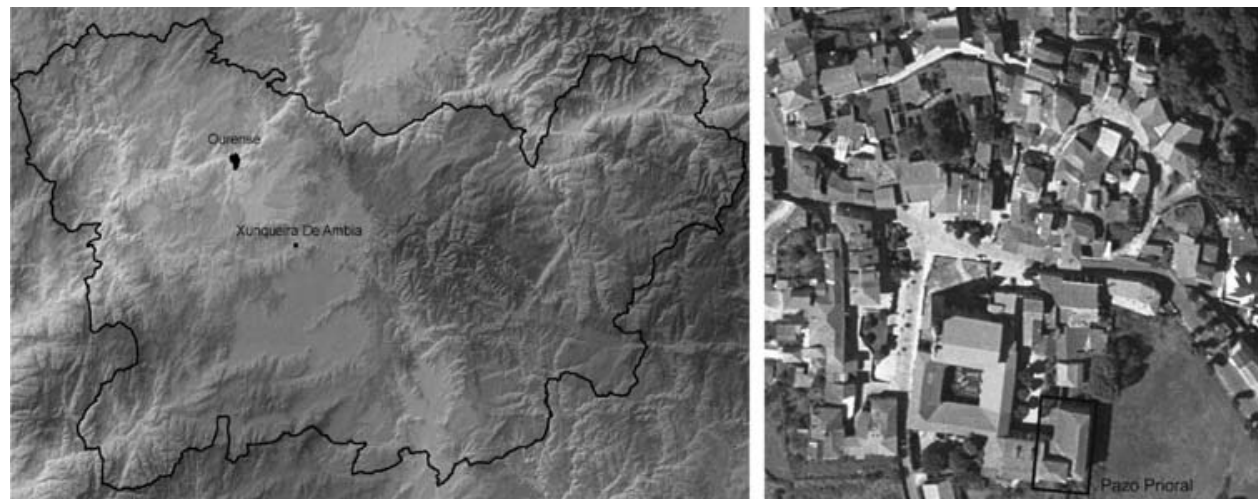

Figura 1: Mapa de la provincia de Ourense con la localización de Xunqueira de Ambía y fotografía aérea con el emplazamiento del Pazo Prioral.

Esta construcción ha sido objeto desde el año 1995 de diferentes proyectos de restauración arquitectónica e investigaciones histórico-arqueológicas asociadas a los mismos. En junio de ese año los arquitectos Recuna y Mendizábal S.C. elaboran el documento denominado "Programa de intervención en la zona monumental de la Colegiata de Xunqueira de Ambía y su entorno" en el que se proponía un uso cultural para el inmueble. Posteriormente, ha sido objeto de una restauración arquitectónica, por encargo de la Dirección Xeral de Patrimonio Cultural, realizada en dos fases: en la primera, desarrollada entre los años 2003 y 2004, se interviene en la cubierta del edificio; en la segunda, desarrollada en el año 2005, se interviene en las fachadas y paramentos interiores y se realizan demoliciones de elementos "discordantes"3.

\footnotetext{
${ }^{3}$ Con respecto a la eliminación de estos elementos, fundamentalmente los muros medianeros que dividían algunas estancias en la primera planta de los sectores A', B', C', E' y F' (para la división del edificio en sectores de trabajo ver figura 4), consideramos que habría sido muy interesante para la lectura del edificio haber podido documentar este tipo de paramentos, ya que en su mayor parte estaban realizados con materiales perecederos siguiendo distintas técnicas. Afortunadamente los arquitectos realizaron un buen reportaje fotográfico de estas divisiones y su proceso de demolición, lo cual nos permite conocer cómo eran, pero hemos perdido la oportunidad de documentar sus relaciones con otras partes del edificio, así como de aportar alguna luz sobre la posible datación de estos elementos, que hemos encuadrado dentro de las distintas fases contemporáneas, teniendo en cuenta los cortes que se han producido en otros muros para su colocación y la posible relación que guardarían con éstos.
} 
Si bien es cierto, actualmente, se estaría llevando a cabo una tercera fase dentro de esta misma restauración. Estas intervenciones arquitectónicas han sido realizadas por los arquitectos redactores del documento al que nos referíamos más arriba.

En el contexto de las intervenciones del año 2005, se encarga a la arqueóloga Nieves Amado la elaboración de un informe histórico-arqueológico, así como el control arqueológico de las intervenciones que afectaban al subsuelo del inmueble. El objetivo de ese informe era "dar a coñecer da forma máis exhaustiva, a analise previa do edificio, mediante a investigación documental do seu contexto histórico, a análise do estado actual e a presentación de propostas de actuación arqueolóxica que nos axuden a alcanzar os obxectivos"4.

Una de las propuestas que se efectuaban en el informe era la elaboración de la lectura estratigráfica de alzados del edificio, dada la complejidad del mismo y las importantes reformas que se iban a llevar a cabo, con la finalidad de identificar su secuencia constructiva. Esta lectura fue realizada por un equipo del Laboratorio de Patrimonio, Paleoambiente e Paisaxe (IIT, USC) (Unidad Asociada al CSIC), conjuntamente con Nieves Amado Rolán, dentro del proyecto de control arqueológico que dirigió esta misma arqueóloga.

\section{ALGUNAS CUESTIONES PREVIAS SOBRE LA DENOMINACIÓN Y FUNCIONALIDAD DEL EDIFICIO}

En el transcurso de aquellos trabajos se optó por denominar el inmueble como Pazo Prioral, siguiendo las recomendaciones realizadas en el Informe HistóricoArqueolóxico. De la investigación que se llevó a cabo sobre el edificio, se desprendía que posiblemente ésta hubiera sido la funcionalidad inicial, que se habría mantenido al menos hasta el primer tercio del s. XVII, momento en que comienza a arrendarse, aunque pudo seguir funcionando como tal hasta la época de la Desamortización. "A través da documentación, da análise visual in situ, dos nomes tradicionais que quedaron na memoria oral dos veciños e das inscripcións que aparecen na propia fachada (...este palacio...), deducimos que o edificio a restaurar, chamado celeiro no proxecto arquitectónico, constitúe xunto co chamado a torre, parte dos restos dos Pazos Priorales ou Casas Priorales, polo que pasamos a denominalo coma Pazo Prioral." (ídem 2005).

Sin embargo, una vez concluida la lectura estratigráfica, se plantean una serie de dudas en relación con esta funcionalidad. Una de las hipótesis que se barajaron fue

\footnotetext{
${ }^{4}$ AMADO ROLÁN 2005.
} 
que la ubicación original del Pazo Prioral podría ser la que hoy está ocupada por el Pazo Episcopal que se construye entre los años 1902 y 1906. A pesar de ello, creemos que el edificio sí estaría relacionado o formaría parte del Pazo Prioral aunque no fuera su construcción principal.

Lo que sí parece claro es que el edificio no fue originalmente un celeiro como se apuntaba en el proyecto arquitectónico, ni creemos que esa haya sido su funcionalidad tampoco durante época moderna. Este término se emplea en algunas zonas de Galicia para denominar a los hórreos, así como una parte constructiva de los mismos (CAAMAÑO SUÁREZ 1999: 16, 20). Begoña Bas, por su parte, apunta que el hórreo es un tipo de celeiro, término que se identifica con un lugar para el almacenamiento de productos agrícolas (ídem 2002: 76).
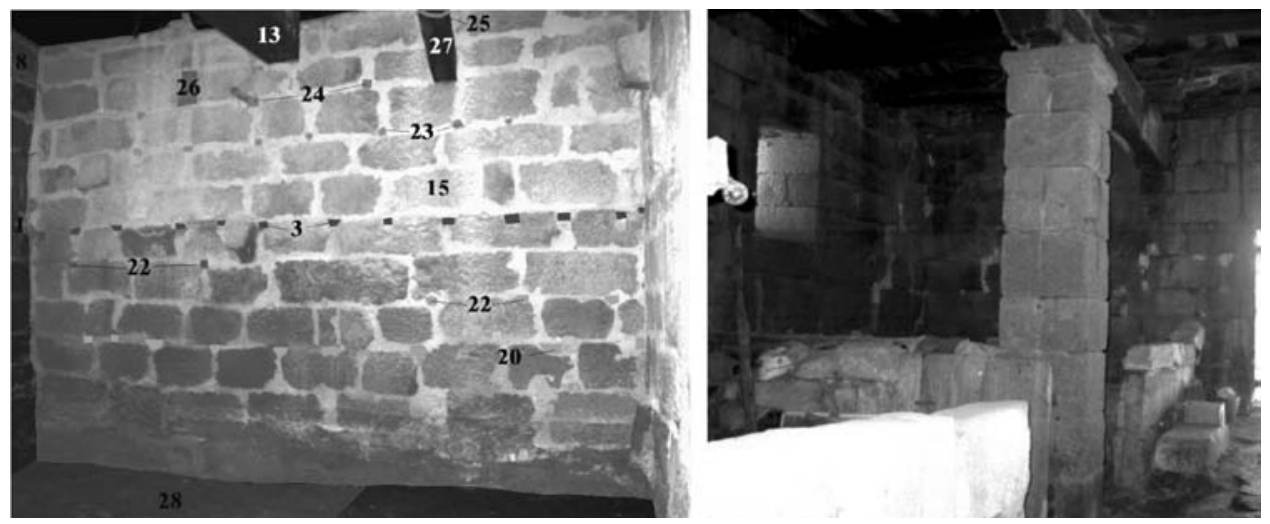

Figura 2: En la imagen de la izquierda se presenta el alzado $\mathrm{N}$ del sector $\mathrm{A}$, en el que se diferencian varias líneas de mechinales que podrían estar relacionadas con una estructura de madera empleada como sequeiro. En la imagen de la derecha, que corresponde al sector C, se aprecian varios muros bajos construidos para habilitar cuadras en este espacio.

Independientemente de cuál sea la funcionalidad exacta de un celeiro, este tipo de lugares de almacenamiento deben presentar unas características concretas que garanticen la buena conservación de los productos: poseer una buena ventilación, estar elevados para impedir la humedad y el acceso de roedores, presentar una orientación determinada... Y estas características no se cumplen en este espacio.

Si bien es cierto, el inmueble ha cambiado de usos a lo largo del tiempo y, con posterioridad a la Desamortización de Mendizábal, las estancias habilitadas en la planta baja del primer cuerpo, han sido adaptadas para cumplir distintas funciones, como cuadras, con la construcción de muretes bajos que separan los espacios y 
rampas para el acceso del ganado. También se aprecian en el sector A varias líneas de pequeños mechinales que pueden servir para la construcción de una estructura de madera elevada en la que se podría almacenar el grano o la paja. Se observan además, entre los mampuestos de los muros que separan las estancias de este cuerpo, restos de espigas, que nos hablan claramente de que en estas zonas se han almacenado este tipo de productos. Pero claramente estas reformas son posteriores a los edificios originales.

Sería necesario seguir investigando para poder determinar la funcionalidad exacta del inmueble en cada una de las etapas identificadas en la lectura estratigráfica.

\section{RESULTADOS DEL ANÁLISIS DE LAS FUENTES Y LA BIBLIOGRAFÍA}

Ante la necesidad de proponer las actuaciones arqueológicas más adecuadas para la restauración del edificio civil bajo los objetivos de documentar, conocer e interpretar la funcionalidad y distintas fases constructivas a lo largo de su historia, y dada la falta de estudios y documentación publicada sobre él $1^{5}$, se realizaron una serie de trabajos de investigación, que constituyeron la primera fase de las actuaciones arqueológicas llevadas a cabo:

- Completa inspección ocular del estado del edificio, con un exhaustivo reportaje fotográfico. De esta inspección no se pudieron extraer datos sobre las distintas fases constructivas, puesto que los muros estaban enfoscados con cal o encintados, pero sí que el edificio tenía varias fases. Esta primera inspección aportó datos cronológicos sobre el edificio a través de las inscripciones en los muros, una aproximación a su funcionalidad y una comprensión general del mismo. ${ }^{6}$

- Pequeña investigación etnográfica mediante entrevistas a los vecinos y párroco, sobre usos y toponimia de los distintos edificios del patio llamado "El Palacio".

- Se recabó información sobre el estado de la cuestión entre los diferentes investigadores relacionados de alguna manera con el conjunto monumental de Xunqueira de Ambía. Las entrevistas a estos investigadores no aportaron

\footnotetext{
${ }^{5}$ Sólo se sabía que había sido casa rectotal antes de su abandono y ruina a principios del s. XX.

${ }^{6}$ Además de la denominación del edificio como celeiro, a la que ya se ha hecho mención, en el proyecto arquitectónico se apuntaba también la posibilidad de que podría haber sido un hospital de peregrinos, dentro del camino sur conocido como "Ruta de la Plata".
} 
novedades en cuanto al uso o cronología del edificio, sobre todo porque el estudio de los edificios civiles no fue objeto de sus investigaciones. ${ }^{7}$

- Se revisaron la mayoría de las fuentes publicadas conocidas.

- Se consultaron varias fuentes originales manuscritas de Xunqueira de Ambía en los archivos Histórico Provincial de Ourense (AHPO) y Diocesano de Ourense (AHDO). Esta vía de investigación fue la que aportó los mejores resultados en cuánto a cronologías, funcionalidades, administración, reformas, personajes, etc.

\section{Contexto histórico general del conjunto de la Colegiata de Xunqueira de Ambía.}

Para una mejor comprensión de la evolución histórica del conjunto monumental de la Colegiata, estructuramos los resultados de la investigación en varias etapas:

Primera etapa: la leyenda

Una antigua tradición afirma que en el s. IV, apareció una imagen de la Virgen en el lugar que ocupaba una laguna denominada Juncaria, erigiéndose allí una pequeña capilla en su honor, que pronto fue objeto de la devoción popular. ${ }^{8}$ Esta hermita será el origen, causa y principio del primitivo monasterio familiar, del posterior monasterio y Priorato de canónigos regulares de San Agustín, de la construcción de la Iglesia-Colegiata, y de la parroquia, villa y municipio de Xunqueira de Ambía.

Segunda etapa: s. X, XI y $1^{a} \frac{1}{2}$ del XII

Hacia el año 955, la capilla se constituye como casa monástica al fundar Gonzalo Froila y su mujer Ilduara, parientes de San Rosendo, con dotación de numerosas propiedades, un convento de haeredes (familiar) de hombres y mujeres célibes, en tierras pertenecientes al señorío de Ambía, de las que eran señores ${ }^{9}$.

Tercera etapa: s. XII-XV

Esta tercera etapa comienza en el 1150 e iría hasta el s. XVI, en el que se realizan grandes reformas. En esa fecha el emperador Alfonso VII hace donación, por Privilegio Real, de la mitad del coto de Xunqueira de Ambía a la Colegiata de Sta María del Sar, en Santiago, y entrega las tierras y monasterio a los Canónigos regulares de la Orden de San Agustín. ${ }^{10}$ Así nace el Señorío y Priorato de Xunqueira de

\footnotetext{
${ }^{7}$ D. Miguel Angel García (Canónigo-archivero de la Catedral de Ourense), Elixio Rivas Quintas (investigador de las distintas rutas del sur del Camino de Santiago, de Xunqueira de Ambía y de la Limia en general), Frei Longinos (mercedario que vivió en Xunqueira de Ambía), Xosé Manuel Cid (antropólogo e investigador de Xunqueira de Ambía). Agradecemos a todas estas personas la información aportada.

${ }^{8}$ GONZÁLEZ GARCÍA 2001

${ }^{9}$ FERNÁNDEZ ALONSO 1905.

${ }^{10}$ PLACER 1938b.
} 
Ambía, de patronato Real, que siempre estuvo compuesto por un Prior y siete Canónigos prebendados. A partir de esta fecha el Priorato no dejará de crecer en tierras y privilegios, por las numerosas donaciones de particulares.

La Colegiata está además situada a la orilla del camino de peregrinación a Santiago, conocido por "Camino de la Plata". El fenómeno de la Peregrinación Jacobea aprovechó la antigua calzada romana que pasaba cerca de Xunqueira. La leyenda de la Virgen de Xunqueira caló profundamente en los peregrinos, que hicieron del lugar un punto obligado de visita y reposo.

En el s. XII, pocos años después de la donación de Alfonso VII, se erige la Iglesia de Xunqueira. El 2 de junio de 1164, el Rey Fernando II en compañía de D. Pedro Seguín, obispo de Ourense, inauguran y consagran la Iglesia-Colegiata, sin estar terminada aún en los arcos formeros, rosetón y techo. ${ }^{11}$

La cuestión del patronato Real dió lugar en el s. XVI a un largo pleito entre Felipe II y el Prior y Canónigos de Xunqueira de Ambía, que se resolvió a favor de Patronato Real.

Cuarta etapa: s. XVI-1 ${ }^{\circ} 1 / 4$ del XVII

Englobaría todo el s. XVI y principios del XVII, hasta la muerte del prior D. Martín de Córdoba, cuando el Priorato es anexionado por Felipe II a la diócesis de Valladolid.

Después de la fundación en el s. XII de la Iglesia y monasterio, el s. XVI constituye la etapa más reformista del conjunto monumental. Esta situación viene dada por el esplendor y riqueza del Priorato, que contaba con abundantísimas rentas. Especialmente los priores Alonso de Piña y Martín de Cordoba, fueron los grandes constructores y reformadores, dándole al conjunto una estructura renacentista que aún se conserva hoy.

El prior D. Alonso de Piña (1513-1544) fue el gran renovador del monasterio: reedifica la Iglesia y construye el claustro, levanta una nueva casa prioral y un hospital para pobres y peregrinos, dota a la Iglesia de un espléndido retablo renacentista, un coro y un órgano. Además recopila todos los documentos, haciendo un archivo que mandó cerrar con tres llaves, el cual se conserva aún hoy en el pazo prioral.

Está considerado como fundador de la villa de Xunqueira de Ambía, porque permite y autoriza poblar de vecinos y hacer casas de vivienda en este lugar, donde sólo existía la Iglesia y las viviendas del Prior y Canónigos. "La villa de Junquera, [...] desde el año quinientos catorce a esta parte se ha ido poblando de casa y vecindad; consintiéronlo los priores, entendiendo ser autoridad y aprovechamiento."12.

\footnotetext{
11 PLACER 1938a.

12 MARTÍN DE CÓRDOBA 1594.
} 
D. Martín de Cordoba (1594-1620) fue el señor y prior más famoso. Llega a Xunqueira en 1594, presentado por Felipe II, después de ganar el pleito sobre el patronazgo real del Priorato. Visita todas las propiedades de la jurisdicción prioral, revisando todos los foros y haciendo otros nuevos, así como cartas de donación, privilegios, etc. Hace un inventario exhaustivo que queda reflejado en un Tumbo ${ }^{13}$.

Reparó la Iglesia Colegiata y la sacristía, construyó el arco de entrada al patio del pazo prioral; junto a éste construyó un edificio, "la Panera", para recoger las rentas de los beneficios, que estaban dispersas por distintas tullas del Priorato. Funda distintas obras pías en favor de doncellas huérfanas y pobres, estudiantes necesitados, que dota con varias rentas según su testamento; deja distintas donaciones a la Iglesia y cabildo.

Fue promovido a Comisario General de la Cruzada y consejero del Reino de España por el Rey Felipe III y se traslada a vivir a Madrid, pero no abandona el cargo de Prior. Fue el último de los priores que residió en los pazos priorales. A partir de aquí, éstos son alquilados al Administrador y Alcalde Mayor.

Quinta etapa: s. XVII-1 ${ }^{a} 1 / 2$ del XIX

Esta etapa está marcada por la anexión del Priorato a la recién creada diócesis de Valladolid por Felipe II. Martín de Córdoba fué el último prior antes de su anexión por bula de Clemente VIII de 1602, no sancionada hasta 1619 por Paulo V. Esta incorporación del señorío y Priorato de Santa $M^{\mathrm{a}}$ de Xunqueira de Ambía a la dignidad y mesa del obispo de Valladolid, dará lugar a muchas discordias y pleitos. Una de las causas de esta anexión fueron las cuantiosas rentas de Xunqueira de Ambía para contribuir al sustento de la mitra vallisoletana.

Así los sucesivos obispos de Valladolid pasaron a ser priores y señores del Priorato de Xunqueira de Ambía. Como señores temporales del señorío fueron dueños directos de las tierras, detentaron el poder jurisdiccional sobre sus habitantes y percibieron todas las rentas y derechos señoriales de vasallaje. Por derecho eclesiástico tenían el poder y mando sobre el cabildo de Canónigos y sobre la Iglesia-Colegiata con el derecho de presentación de parroquias, beneficios y capellanías, pero este mando eclesiástico estaba limitado y controlado por el poder canónico de los obispos de Ourense. No residían sus pazos de Xunqueira y delegaban la administración al Alcalde Mayor y a un arrendatario de los foros que le pagaba las rentas en dinero.

Sexta etapa: S. XIX-XX

Esta última etapa viene marcada por la desintegración del señorío y Priorato tras la desamortización de Mendizábal en 1837 y por la conversión de la Colegiata de Xunqueira de Ambía en simple parroquia de término en 1853, dentro de la diócesis de Ourense.

\footnotetext{
${ }^{13}$ MARTÍN DE CÓRDOBA 1594.
} 
Las condiciones abusivas de los foros, la no renovación de los mismos, junto con malos años de cosechas, pestes y levas militares dieron lugar a una situación de desahucio que dará lugar a la posición regalista de las "manos muertas". Esto llevará a la extinción de los señoríos en 1811 en las Cortes de Cádiz y a las distintas leyes desamortizadoras del s. XIX.

El decreto desamortizador de Mendizábal del 29 de julio de 1837, será la causa de la desaparición y extinción del Priorato de Xunqueira. Por él se suprimieron los derechos jurisdiccionales, diezmos, primicias y demás prestaciones; de las nueve prebendas y de los beneficios que el prior, obispo de Valladolid, y los Canónigos tenían sobre las parroquias anexas. Todas las propiedades y bienes de este Priorato se adjudican a la Nación Española, menos la Iglesia Colegiata y las casas del párroco con sus huertas y jardines adyacentes ${ }^{14}$. Estos últimos bienes son precisamente los únicos que se conservan hoy como propiedad eclesiástica.

El 31 de marzo de 1853 D. Luis de la Lastra y Cuesta, obispo de Ourense, decreta: "Queda reducida la iglesia colegiata de Xunqueira de Ambía a parroquia de término, desde ahora en adelante, con la misma advocación de Santa María...”15.

Este tipo de clasificación es de primera categoría dentro de las parroquias, con una nutrida plantilla compuesta por abad párroco, ecónomo, coadjutor, beneficiados y sacristán. Queda extinguido el cabildo colegial.

Por la ubicación cerca de Ourense, con capacidades termales y saludable clima, que le valieron el sobrenombre de Vila Sana, los obispos de Ourense decidieron su elección como lugar de descanso de la sede episcopal de Ourense. El obispo Pascual Carrascosa mandó construir, a principios del s. XX (1902-1906), una Casa Episcopal. Esta casa fue ocupada primero por los Hermanos de las Escuelas Cristianas, que establecieron un colegio que marca un período de florecimiento cultural, y en 1928 se entrega a la Orden Mercedaria, que rigió la parroquia hasta comienzos de noviembre de 2003.

\section{El priorato y señorío}

EL Priorato de Xunqueira de Ambía, estaba situado geográficamente en "Tierra de Limia"16, entre Allariz y Ambía, en la cuenca del Alto Arnoya. Este es el núcleo original, pero las propiedades se extendían mediante cotos y lugares, hasta la Sierra de San Mamede por el E, la Limia actual y el Valle de Monterrey por el S, llegando hasta la Gudiña.

\footnotetext{
14 BARROS GUEDE 2004, 54.

15 BARROS GUEDE 2004, 118.

${ }^{16}$ La Tierra de Limia ocupaba una superficie mucho mayor que la actual, abarcando casi todo el centro y sur de la provincia de Ourense.
} 
Los señoríos eclesiásticos son donaciones de los reyes a obispos, abades y priores, mediante cartas de privilegio, por las que adquiere la propiedad de las tierras y lugares acotados, con dominio directo sobre ellas y con poder jurisdiccional civil y criminal sobre sus foreros y vasallos.

El Emperador Alfonso VII crea los señoríos eclesiásticos en Galicia; monasterios cistercienses como los de Oseira en 1137, Melón y Sobrado de los Monjes en 1142 y monasterios y Prioratos de Canónigos regulares de San Agustín, entre ellos el de Santa María la Real de Xunqueira de Ambía.

Los priores daban en arriendo o foro las tierras, con derecho de usufructo a cambio de una renta en especie o dinero, por tiempo de varias voces, o vidas de Reyes. Ejercían la jurisdicción judicial y administrativa, casi siempre a través de administradores civiles: Alcaldes Mayores, Jueces, Alguaciles, Escribanos, etc., siempre nombrados por ellos.

En el s. XVI las rentas del prior ascendían a cinco mil ducados y los Canónigos percibían cada uno de ellos unos 200 ducados al año.

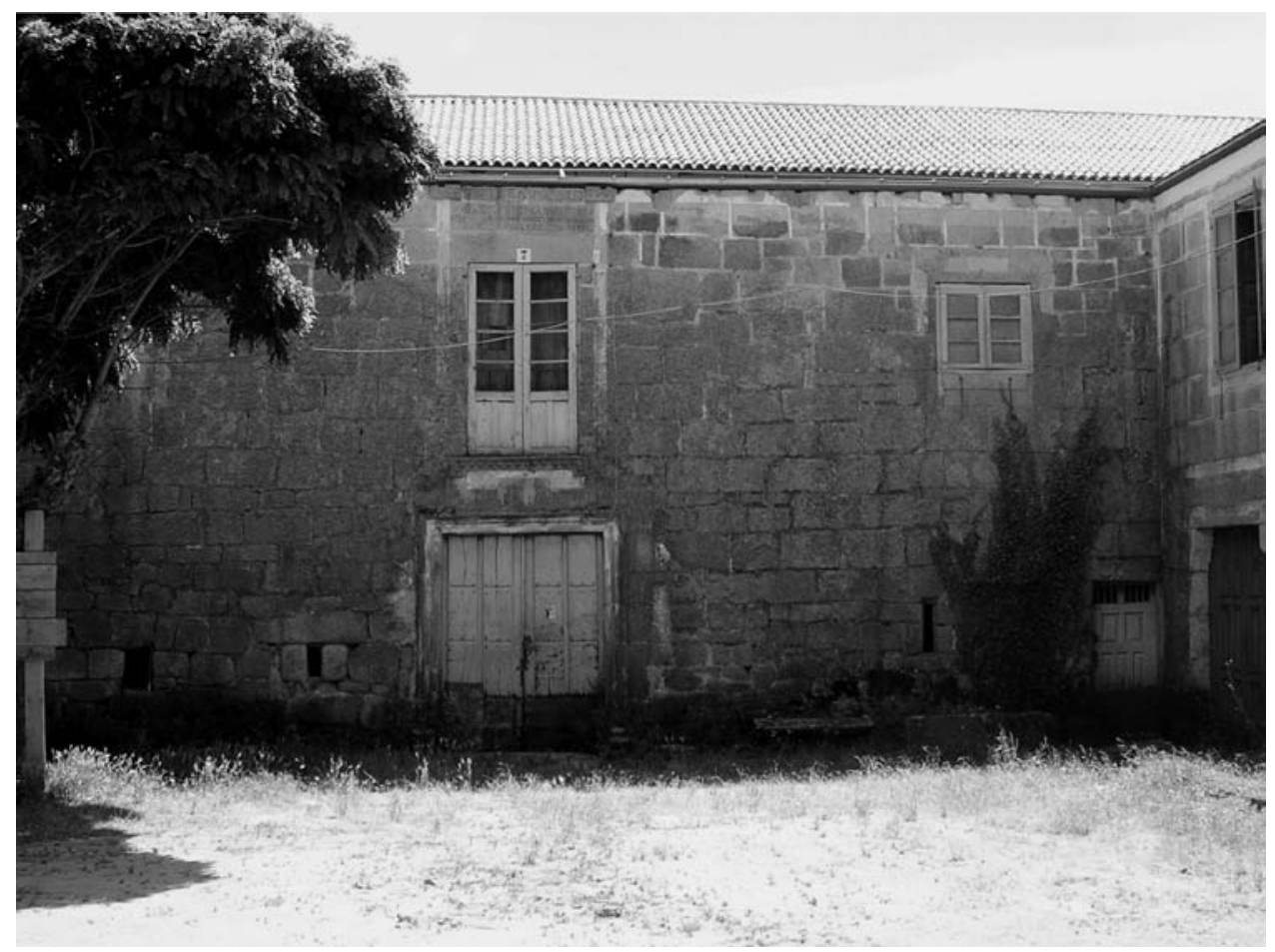

Figura 3: Fachada principal del Pazo Prioral. 


\section{Los pazos o casas priorales}

El lugar físico de los Pazos o Casas Priorales se sitúa en la esquina SE del patio que cierra por el E el conjunto Monumental de la Colegiata de Xunqueira de Ambía. Ocupan una gran superficie, y posiblemente, antes de la Desamortización del s. XIX, estarían constituidos por el Pazo propiamente dicho como vivienda del Prior, y por una serie de edificios auxiliares además de otros servicios como fuente y cárcel, todo en torno a un patio cerrado por un arco del s. XVI, con el escudo de Felipe II, que aún existe hoy. Adosado a él hay un local, conocido como "Panera" 17 con el escudo de armas de Martín de Córdoba y una inscripción laudatoria a Felipe II, que fue Pósito de Labradores, fundado en 1594 por el prior Martín de Córdoba para dejar simiente de grano a los labradores pobres, por la que pagaban de réditos un "copelo por ferrado". Hoy es la sede de la Asociación de Veciños Vila Sana. En el frente sur del patio se alza la Residencia Episcopal, construida entre 1902 y 1906 y conocida como "Convento", que fue residencia de los Padres Mercedarios, como ya se comentó.

Este patio, llamado por los vecinos "el palacio", constituye la parte civil de la Colegiata, como centro de poder del señorío eclesiástico jurisdiccional; donde se recogían las numerosas rentas y se administraba justicia.

El Pazo Prioral primitivo debió de ser obra del s. XII, reformado en 1529 y en 1594 por los priores Piña y Córdoba respectivamente y rehecho en 1853 por el arcipreste de Ourense Rafael Calabozo para convertirlo en casa rectoral. Estos datos coinciden además con los resultados de la lectura estratigráfica.

\section{LA ACTUAL CONFIGURACIÓN DEL EDIFICIO}

Actualmente, el inmueble está formado por una planta en L, con el lado mayor orientado en sentido N-S, al cual se han adosado en distintas épocas varias construcciones en su fachada $\mathrm{W}$ que han modificado la configuración en esta zona del edificio primitivo. Se articula, a su vez, en tres grandes cuerpos, dentro de los cuales se ha realizado una división en sectores de trabajo, a la que nos referiremos a lo largo del presente texto:

- Primer cuerpo: longitudinal orientado en sentido N-S y articulado en dos pisos. Contaba, al inicio de la restauración que se lleva a cabo en el año 2005, con tres estancias en ambos pisos. Se han diferenciado como sectores A, B y C en el planta inferior, y A', B' y C' en la planta superior. A él se adosa en la fachada $\mathrm{E}$ un gran balcón corrido, sustentado por cuatro contrafuertes.

\footnotetext{
${ }^{17} \mathrm{Al}$ que nos referíamos anteriormente.
} 


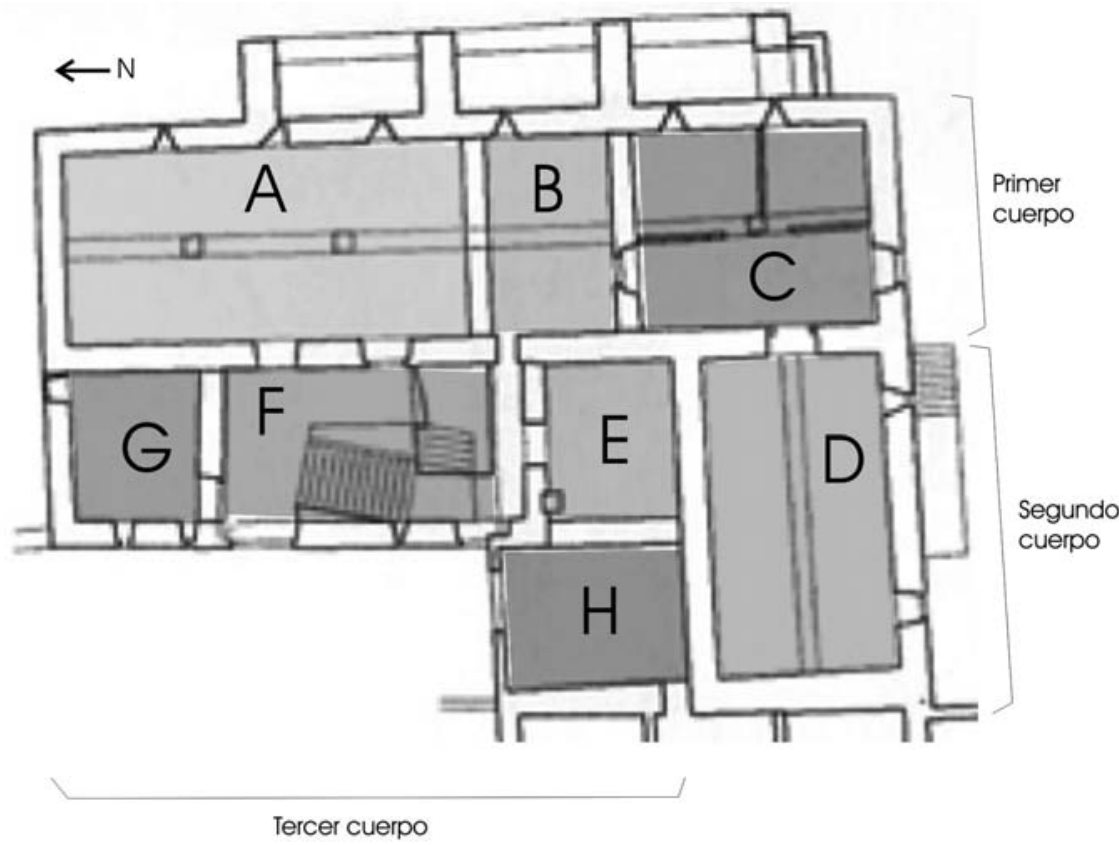

Figura 4: Planta baja del edificio, en la que se han delimitado los sectores y cuerpos diferenciados durante el proceso de trabajo.

- Segundo cuerpo: longitudinal, de menores dimensiones que el anterior, orientado en sentido E-S, cuenta con tres pisos y no posee divisiones interiores. Se ha diferenciado como sector D, D' y D", según la planta.

- Tercer cuerpo: longitudinal, adosado a la fachada $\mathrm{W}$ del primer cuerpo y $\mathrm{N}$ del segundo. Se articula en dos alturas y tres estancias en cada planta, una central de mayores dimensiones que incluye la puerta principal y la escalera, y dos laterales de menores dimensiones. Se han diferenciado, desde el S, la primera habitación como sector E y E', según la altura; la segunda habitación como sector, F y F'; y la tercera como G y G'.

Finalmente, al actual garaje, que se localiza entre los sectores D, E y el edificio construido hacia el W a principios del s. XX, se le ha otorgado el sector $\mathrm{H}$.

\section{LA ESTRATIGRAFÍA HORIZONTAL}

En el proyecto arquitectónico de 2005, se preveía retirar, con control arqueológi$\mathrm{co}, 30 \mathrm{~cm}$ de profuncidad del suelo en todas las estancias del edificio, para dotarlos 
de nuevos suelos y servicios, adecuados a su futuro uso cultural. Pero no era posible retirar esos $30 \mathrm{~cm}$ en todas ellas, ya que las cotas de relleno eran variables. Nuestro objetivo principal consistió en localizar los suelos originales y documentar los distintos depósitos y materiales generados por los diferentes usos, reformas y fases constructivas históricas. Para ello optamos por retirar los rellenos por niveles según la deposición original, de esta manera obtuvimos un mayor conocimiento de la estructura, evolución y cambios de uso de las estancias de la planta baja del edificio.

Los resultados más destacables de esta intervención fueron los siguientes:

- la aparición de dos pavimentos de piedra de similares características, uno en la esquina NW del sector A, compuesto de cantos y bloques de granito que delimitan sectores cuadrangulares, y otro en la puerta románica que comunica los sectores A y F, de cantos de granito y de planta abocinada. Estos dos pavimentos son contemporáneos y pueden encuadrarse de momento, en una de las reformas del s. XVI. ${ }^{18}$ Además, un empedrado de bloques cuadrangulares de granito muy desgastados, situado por debajo del actual empedrado, también de granito, del sector G. Correspondería a una fase de ampliación del edificio posterior a la románica, posiblemente a época moderna (ver figura 5).
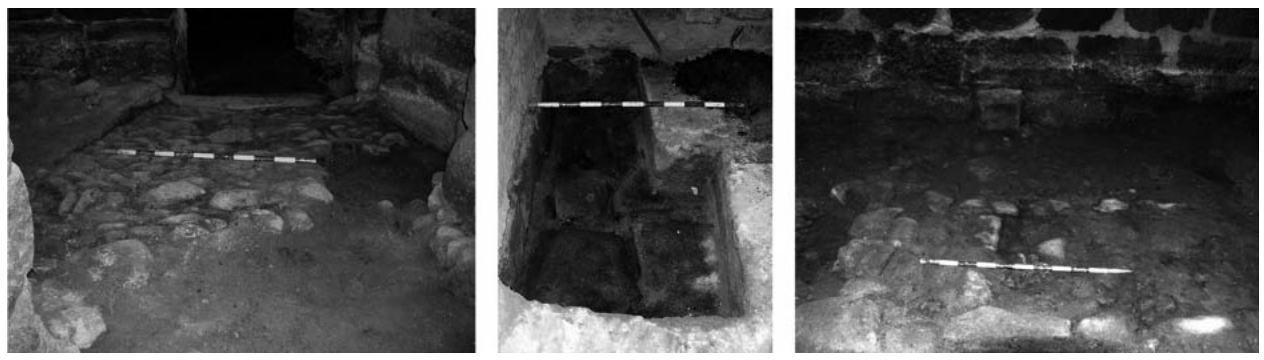

Figura 5: Pavimentos exhumados en las estancias A, G y F, respectivamente.

- Una estructura en el patio exterior del edificio, al W y en paralelo a la fachada principal, que consiste en la delimitación mediante un murete de piedra, similar a un antepecho, de una zona extensa delante del edificio, que se prolonga más al $\mathrm{N}$ del final de la fachada. Constatamos la existencia de al menos dos piedras verticales con decoración, y alguna zona que parece contener un enlosado de granito (ver figura 6).

${ }^{18}$ BLANCO - GARCÍA 2006. 

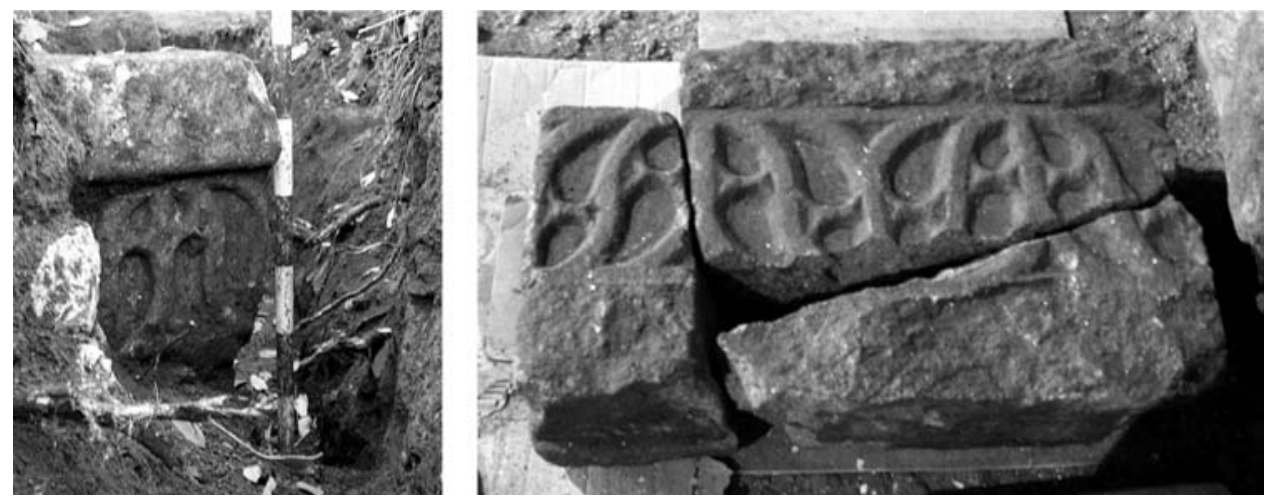

Figura 6: Estructura y pieza descubierta en la zanja exterior, en la fachada W del Pazo Prioral.

- Varias piedras con decoración, adscribibles desde el románico al s. XVI, rescatadas de un sedimento moderno en la estancia A, que parece fueron desestimadas y amortizadas en alguna reforma del edificio. Son una basa de columnita románica, varios fragmentos curvados con decoración de molduras nervadas terminadas en picos, de un arco geminado, posiblemente de una ventana, y un fragmento que parece de una nervadura de bóveda (ver figura 7).
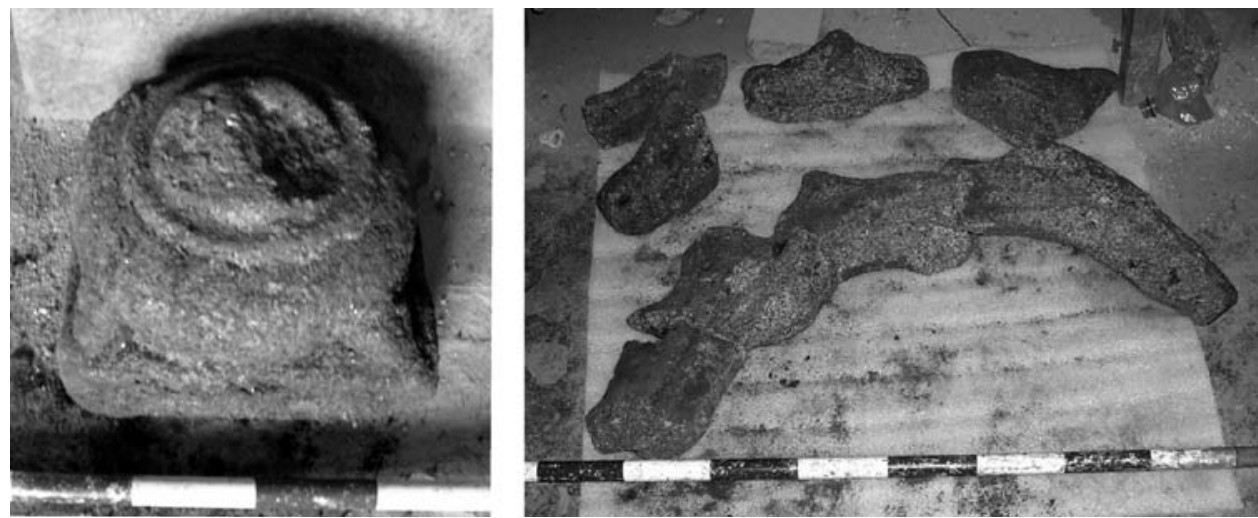

Figura 7: Algunas de las piezas recuperadas en la estancia A.

- En cuanto a la funcionalidad de las estancias de la planta baja, se constató que al menos en el pasado reciente (s. XIX y XX), estuvieron dedicadas a usos de cría y estabulación de animales domésticos principalmente. En los sectores $\mathrm{A}, \mathrm{B}$ y $\mathrm{C}$, se documentaron estructuras relacionadas con este uso: 
pequeños muretes bajos que compartimentan el espacio en cubículos o cortellos; o una rampa que salva el desnivel exterior e interior en la estancia A y que serviría para conducir el ganado al interior.

- Otra singularidad fue la aparición de varias fosas cuadrangulares bajo el pavimento en las estancias G y D, ambas relacionadas con la Guerra Civil, bien para esconder productos de contrabando, bien para esconder personas, según los vecinos.

\section{PRIMER EDIFICIO MEDIEVAL}

fase constructiva I
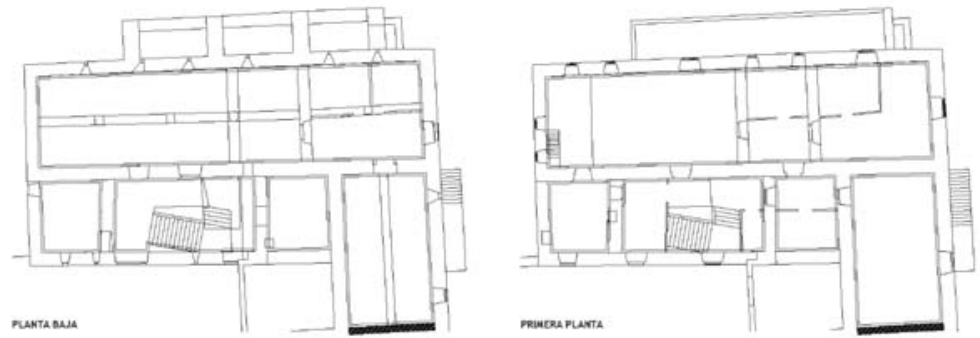

fases constructivas lla y llb
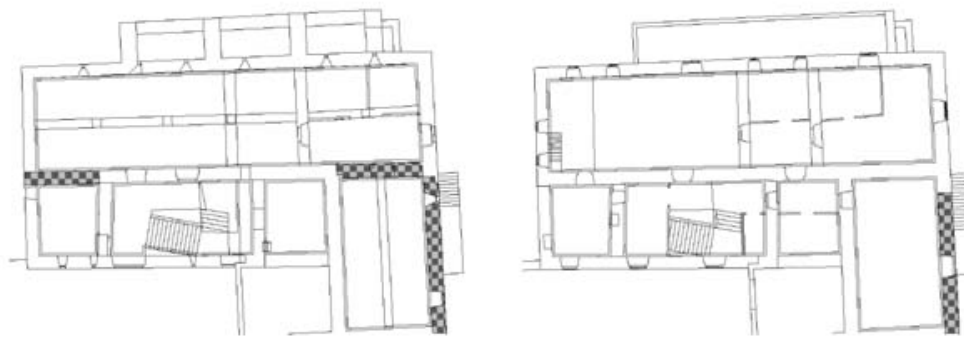

fases constructivas IIla, IIIb, IIlc, IIId y IIle
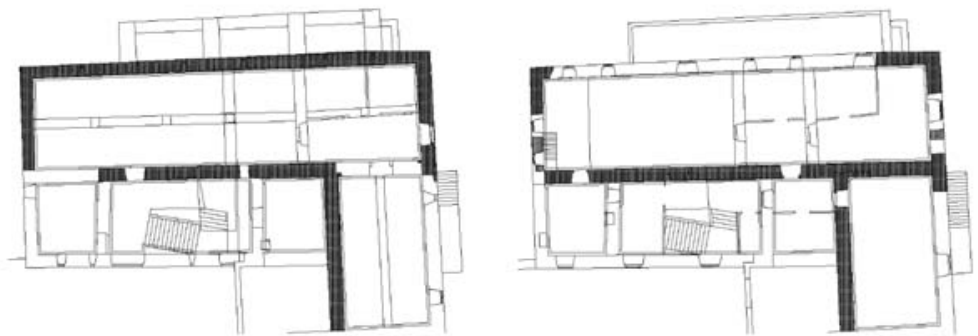

Figura 8: Planta del edificio, en la que se han representado las fases medievales documentadas. 


\section{LA ESTRATIGRAFÍA VERTICAL}

En este apartado se recogen las interpretaciones resultantes de la lectura de alzados. Las fases constructivas

Se hará una descripción del edificio teniendo en cuenta su evolución constructiva. Los edificios medievales

La actual planta en L de la construcción corresponde a época medieval, aunque dentro de esta planta se han identificado tres momentos constructivos distintos. A esta etapa pertenecen las fases I, II y III, vinculándose a la tercera la planta en L.

Teniendo en cuenta estas fases, se han identificado los restos de tres posibles edificios de época medieval, el tercero de ellos perteneciente probablemente al S. XII, por el tipo de decoración que presentan algunos de los elementos identificados como pertenecientes a esta etapa (ver figura 9). Este tipo de decoración se encuentra en relación con los modelos empleados por los talleres mateanos que irradian del foco compostelano. Como ya se comentó, Xunqueira de Ambía estuvo vinculada a la Colegiata de Santa María del Sar (Santiago de Compostela) en la que se ha documentado un taller del Maestro Mateo trabajando en estas mismas fechas. No creemos, sin embargo, que entre el segundo y tercer edificio exista una importante diferencia cronológica, ya que los aparejos empleados son muy similares.

En el caso del segundo edificio podría tener una planta rectangular, y sin duda era de mayores dimensiones que lo que se conserva en la actualidad, ya que, como

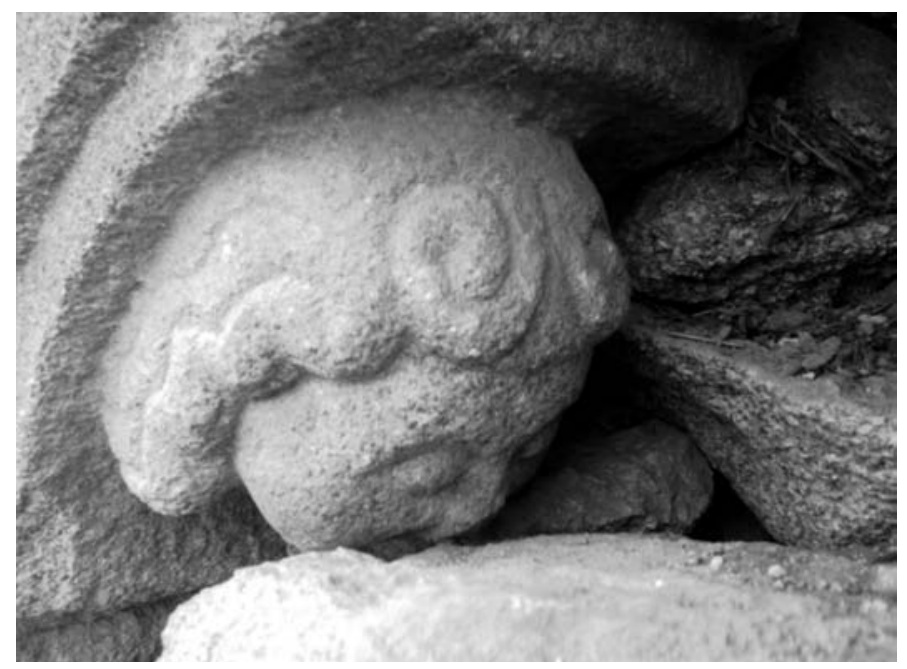

Figura 9: Mocheta izquierda de la ventana de la fachada E del sector D", decorada con una cabeza humana de estilo "mateano". 
se puede observar en la fachada N (figura 10), la UE001 ${ }^{19}$ está cortada y continuaría hacia el $\mathrm{N}$. Teniendo en cuenta las distintas orientaciones de los vanos documentados para esta fase (puerta y saetera) con respecto a la fase III y la localización de

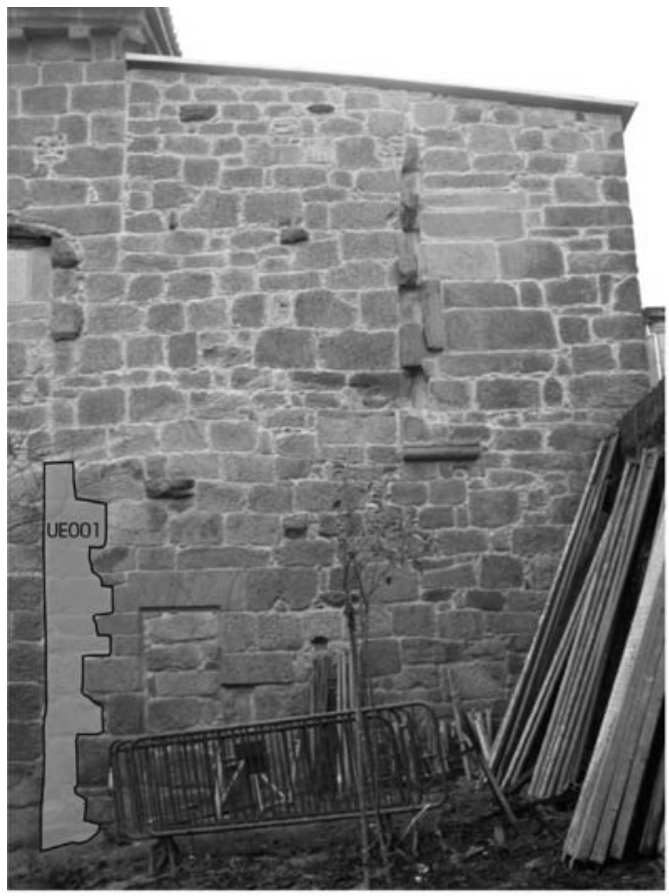

Fachada $\mathrm{N}$ del edificio

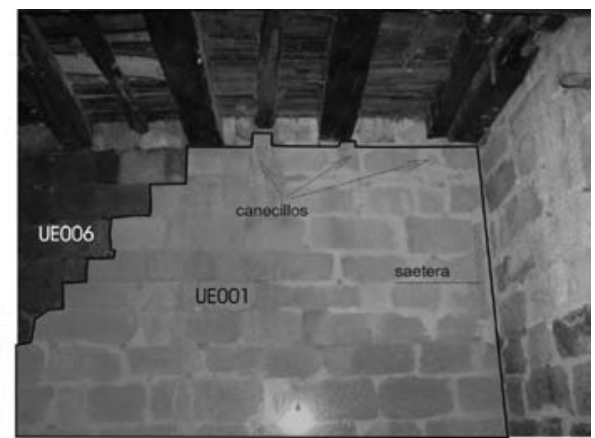

Alzado $\mathrm{W}$ interior de sector $\mathrm{A}$
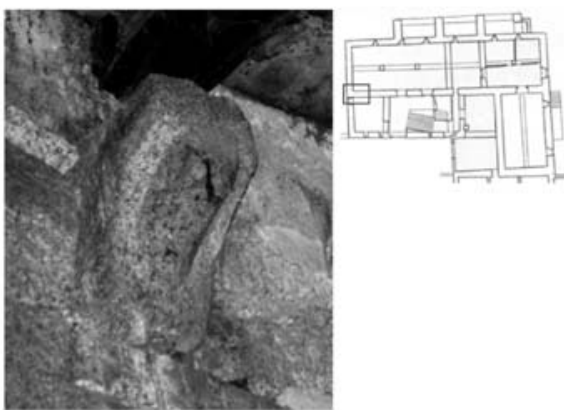

Detalle de uno de los canecillos

Figura 10: Detalle de la UE001, correspondiente a la fase medieval II, en la que se conservan parte de los canecillos de la que sería, posiblemente, su fachada E.
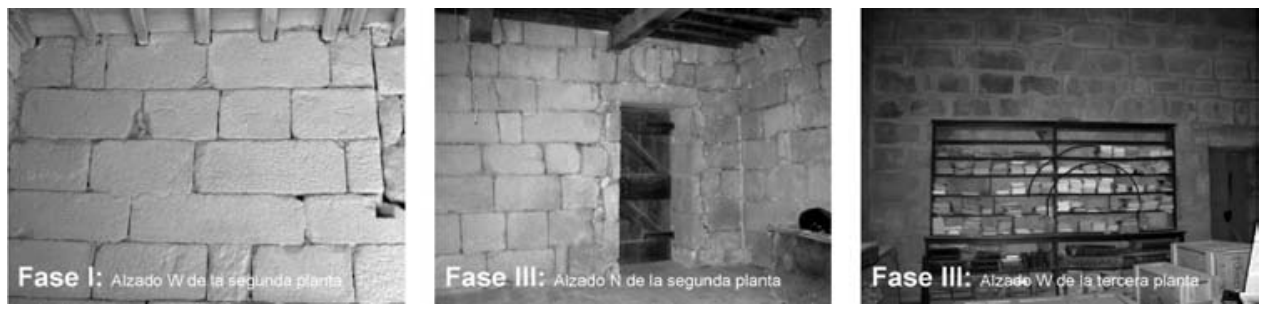

Figura 11: Aparejos correspondientes a las fases medievales I y III.

${ }^{19}$ La abreviatura "UE" se refiere a Unidad Estratigráfica, entendida como unidad menor susceptible de ser registrada, con individualidad y homogeneidad estratigráfica y formada por acciones constructivas o destructivas. 
las UE vinculadas a esta fase, el edificio ocuparía espacialmente al menos la zona en la que ahora se localizan los sectores D, E, F, G y, posiblemente H, es decir, su fachada E sería el actual alzado W interior de los sectores A, B y C. Por lo tanto, parte de este segundo edificio se reutiliza en la construcción del tercero, del mismo modo que la fase II se apoyaría sobre la I. Aún así, si no se realiza una excavación arqueológica en la zona de la fachada $\mathrm{N}$ y en el patio localizado delante del edificio, no es posible definir con mayor exactitud cuál sería la planta de la fase II. Del mismo modo, al conservarse únicamente un alzado vinculado a la fase I dentro de la estructura del inmueble analizado, no podemos definir cuál sería la planta de ese primer edificio.

\section{Las transformaciones de época moderna}

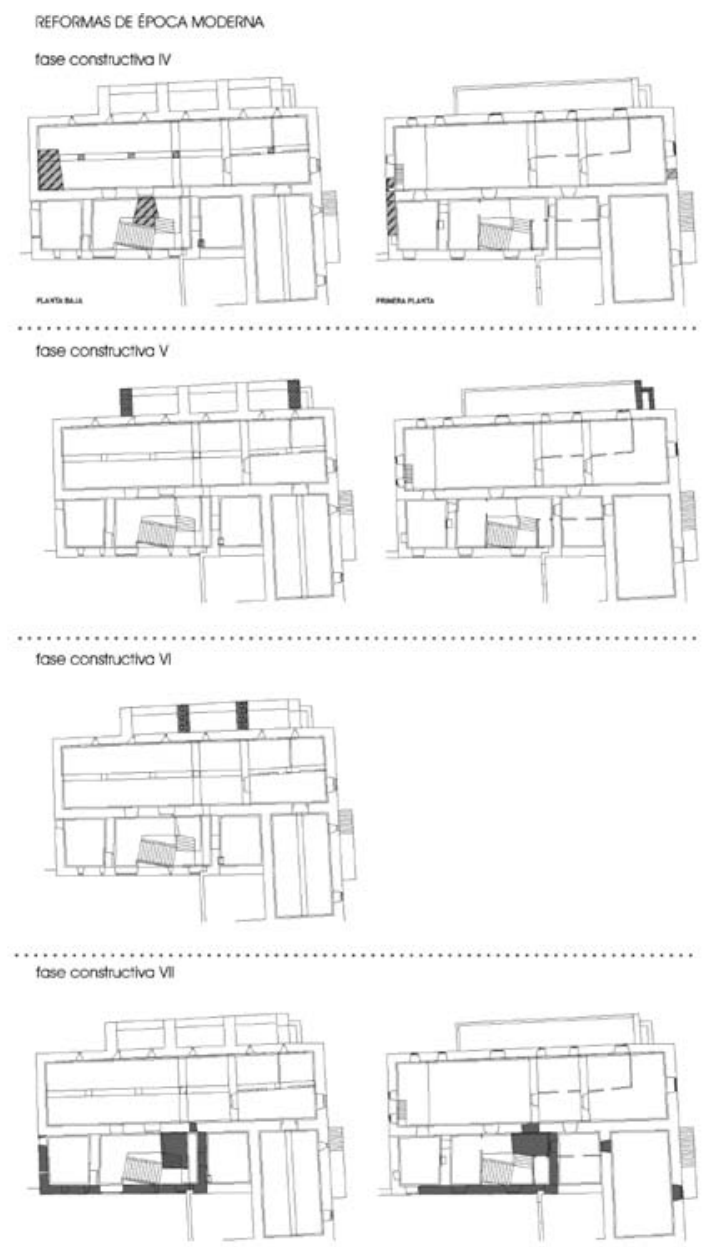

Figura 12: Planta del edificio, en la que se han representado las fases modernas documentadas. 
El s. XVI, como ya se apuntó, constituye la etapa más reformista del conjunto monumental, con motivo del esplendor y la riqueza del Priorado. Concretamente se hacía hincapié en las figuras de los priores Alonso de Piña (1513-1544) y Martín de Córdoba (1594-1620), como promotores e impulsores de obras, reformas y renovaciones, las cuales han quedado reflejadas en la estratigrafía del edificio. Ya a principios del s. XVII el Priorado es anexionado por la Diócesis de Valladolid, para este siglo no se documentan, sin embargo, noticias de importantes reformas en el edificio.

Dentro de esta etapa hemos englobado las fases IV, V, VI y VII, en las que se documenta una importante actividad constructiva, que se traduce en algunas reformas en los espacios interiores y en la ampliación del edificio hacia el W, ganando lo que hemos denominado como tercer cuerpo en la descripción inicial.

\section{Fase constructiva IV}

En época medieval, concretamente en la fase III, recorrería la fachada W un balcón o pórtico, posiblemente sustentado sobre una estructura de madera, de la que
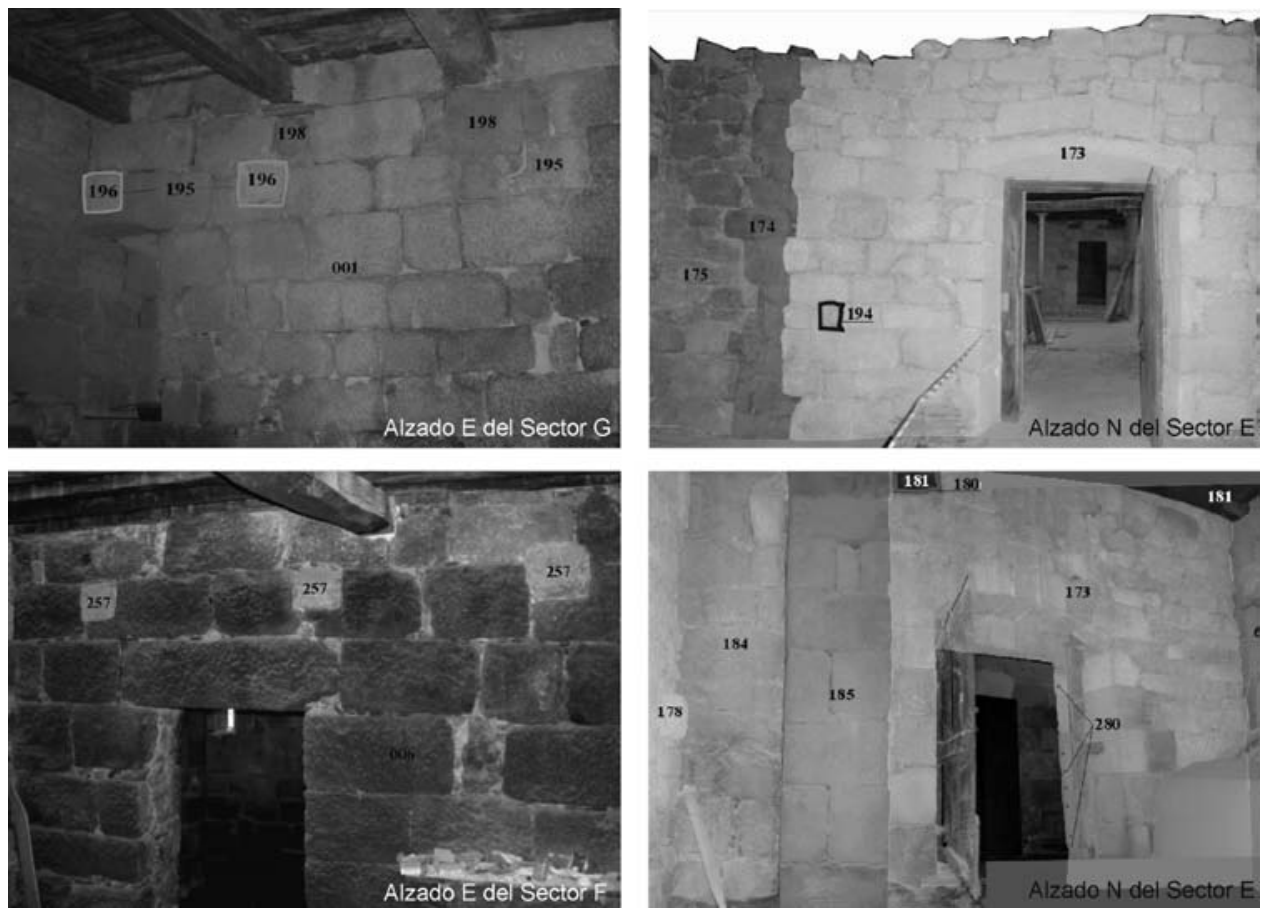

Figura 13: Las dos imágenes de la izquierda corresponden a la fachada $\mathrm{W}$ de las fases medievales; los mechinales cegados por la UE257 son de obra y coetáneos a la UE006, los mechinales UE195 son coetáneos a los anteriores y están abiertos en la UE001, vinculada a la fase II. Sobre ellos, se sitúan los mechinales UE198 que corresponden a la fase IV. En las imágenes de la derecha, las UE174 y 185 corresponden a la petrificación del balcón en esa fase. 
son reflejo los mechinales constructivos diferenciados en la UE006 (sector F) y los mechinales abiertos en la UE001 (UE195 del sector G).

Pero durante la lectura se documenta una segunda línea de mechinales sobre los anteriores (UE198), un muro que cierra la parte alta de la fachada N (UE143) que presenta en la parte baja una especie de antepecho con moldura, y un pilar en el sector E (UE185) de las mismas características que los que se conservan en los sectores A, B y C (UE011) (ver figura 13). Todos estos elementos se encuentran siguiendo la misma trayectoria. Estos datos nos han llevado a plantear la hipótesis de que en la fase IV se petrifica el balcón o pórtico de madera de la fase anterior, apoyándolo ahora sobre grandes pilares, de este modo se construiría un corredor porticado delante de la fachada $\mathrm{W}$ medieval.

Esta estructura ha dejado también algunas otras huellas en las habitaciones E y E', concretamente las rozas y mechinales o los restos del interior de un muro. Creemos que estarían relacionadas con la existencia de un muro que cerraría la fachada $\mathrm{W}$ de esta habitación en la planta alta.

La similitud entre el pilar al que hacíamos mención y los grandes pilares que recorren el interior de la planta baja de los sectores A, B y C, sobre los que se apoya un suelo de madera del segundo piso, soportado por una viga maestra, grandes vigas transversales y pontones, nos ha llevado a incluirlos dentro de la misma fase. Los mechinales para encastrar estas vigas están cortando los muros medievales. Se trata de pilares de planta cuadrada rematados en un capitel con muy poco desarro1lo, realizados en sillería isódoma dispuesta a soga y tizón.

A este momento corresponde igualmente la construcción de una estructura abovedada, que salvaría el acceso al sector A, a través de la puerta medieval de la fase III. De ella se conserva en alzado el arranque de la bóveda y, en planta, una estructura abocinada hacia el exterior y el pavimento realizado con cantos, igual al que se ha documentado durante las fases de limpieza del suelo en la esquina NW del sector A. Esta bóveda sólo tiene sentido bien para magnificar la entrada principal o bien si tuviese que soportar una estructura pesada, como la petrificación del balcón o una escalera de acceso a la segunda planta desde el exterior. Debemos indicar que no hemos documentado las huellas de una escalera en los espacios interiores, por lo tanto, debería accederse a este segundo piso desde fuera. La actual escalera está compuesta por piezas que pertenecen a dos o tres tipos de escaleras distintas.

Al mismo tiempo, el suelo interior empedrado estaría construido de forma coetánea o posterior a los pilares que recorren interiormente el edificio en la planta baja. Por lo que se había limpiado hasta el momento en el que se efectuó la lectura de alzados, parece que se habría realizado de forma coetánea a los pilares. 

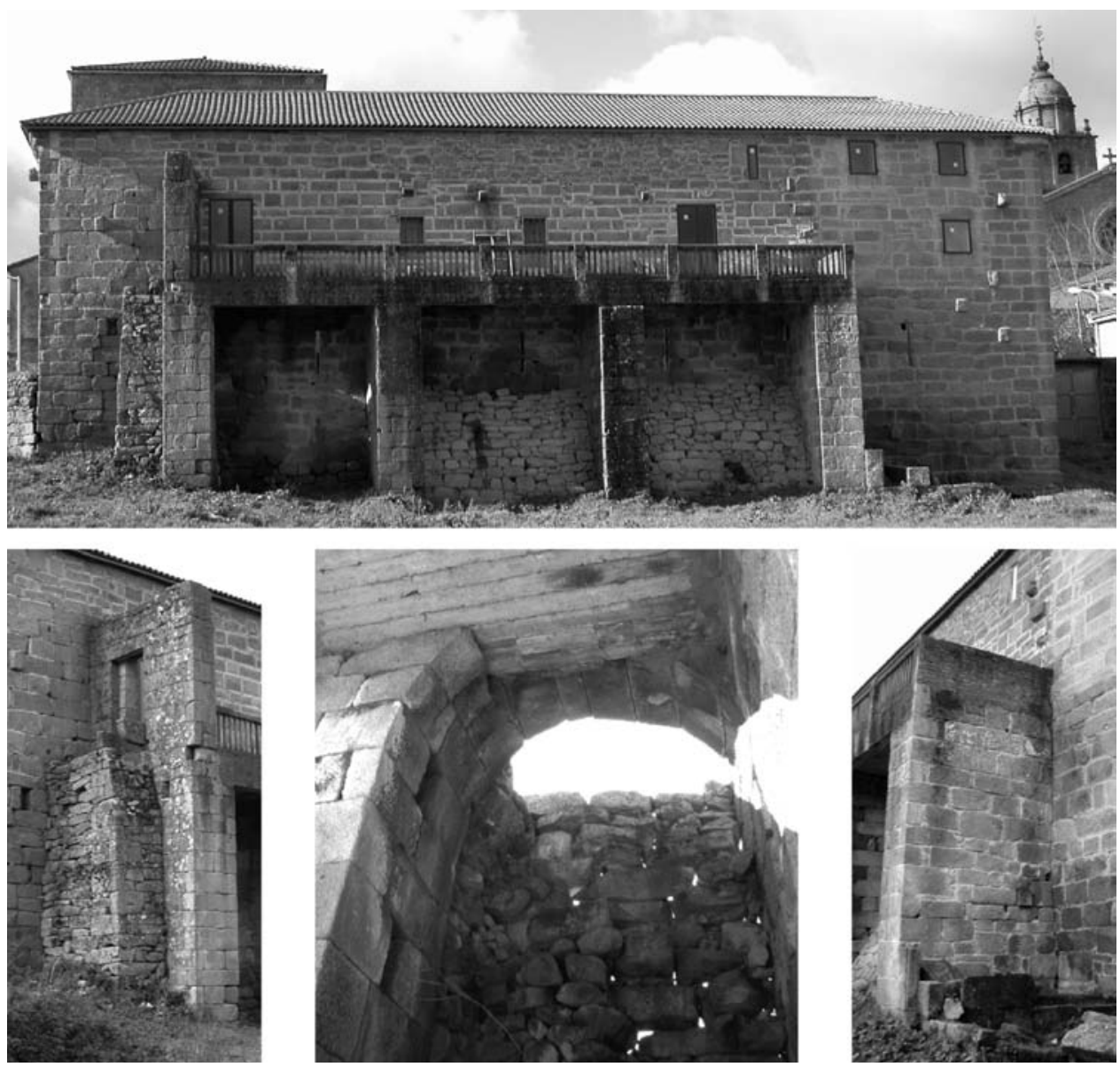

Figura 14: En la imagen superior se puede observar el balcón situado sobre los contrafuertes de la fachada E del Pazo. En las imágenes inferiores se presenta un detalle de estos contrafuertes, las fotografías de la izquierda y central corresponden al contrafuerte $\mathrm{S}$ y la de la derecha al $\mathrm{N}$.

Hemos identificado esta etapa con las reformas realizadas por el Prior Alonso de Piña, Prior de la Colegiata de Santa María de Xunqueira de Ambía entre 1513 y 1544.

Fases constructivas $V$ y VI

En la fachada E se localizan cuatro grandes contrafuertes que soportan un balcón. Éstos corresponden a dos fases constructivas distintas, ya que, aunque son muy similares entre sí, existen diferencias entre los aparejos que se emplean en cada uno de ellos. Los dos contrafuertes exteriores pertenecen a la fase $\mathrm{V}$ y los centrales a la VI (ver figura 14). 
Los contrafuertes exteriores se habrían construido con una doble intención, por un lado, ejercer de elementos sustentantes para un balcón y, por otro, como contrafuertes para la fachada $\mathrm{E}$ del edificio medieval, que presenta diferentes deformaciones por problemas estructurales. En el caso del balcón, que recorrería gran parte del segundo piso, estaría cerrado en sus lados N y S. En el cierre del lado S se dispone una letrina sustentada sobre unas ménsulas que aún se conserva. Creemos que posiblemente los cierres laterales del balcón hayan contribuido a que se conservaran a ambos lados de los mismos los muros medievales, mientras se desploma la fachada en la zona situada entre ellos, habiendo actuado como sostén del muro. El contrafuerte del extremo $\mathrm{N}$ es macizo, pero el $\mathrm{S}$ se construye a modo de arbotante, con un arco que engarza sobre el dintel de una saetera de la fase medieval.

Los problemas estructurales a los que nos hemos referido, creemos que motivarían la construcción de unos segundos contrafuertes, bajo el balcón en su zona central, de aparejo más cuidado que los anteriores. De este modo, en la planta baja la fachada se mantuvo en pie al haberse adosado los dos contrafuertes centrales.

Estos problemas están motivados por varias causas: una insuficiente cimentación (se emplaza en una zona de abundante agua y niveles freáticos altos), la falta de xuntoiros o tizones (que contribuyen a atar las dos hojas del muro) y la propia altura de la misma, la de mayores dimensiones de todo el conjunto. El desplome de la totalidad de la fachada ha sido evitado gracias a las distintas medidas que se fueron adoptando a lo largo del tiempo: los contrafuertes, los muros medianeros interiores o los muros en talud exteriores. Pero en el interior se apreciaba que las dos hojas del muro en alzado $\mathrm{E}$ del sector A estaban separadas, produciéndose un importante abombamiento en la parte media del muro.

Fase constructiva VII

Esta etapa afecta fundamentalmente a la fachada W. Hemos identificado esta fase constructiva con las reformas realizadas por el Prior Martín de Córdoba, en torno a finales del s. XVI.

En este momento se cerraría por completo el corredor porticado de la fase IV, adelantando la fachada W y articulando en esta zona dos plantas. Desconocemos qué tipo de puerta tendría esta fachada, ya que la actual puerta principal, sobre la cual se dispone el siguiente epígrafe "1594. EL PRIOR DON MARTÍN DE CORDOVA", habría sido recolocada o trasladada aquí en la fase VIII.

La hipótesis que barajamos es que esta puerta originalmente presentaría una luz mayor que la actual, y que por lo tanto provendría de otra localización, con lo cual el epígrafe no fecha el muro. Cabe la posibilidad de que su ubicación original fuera el espacio en el que a principios del s. XX se construye el palacio episcopal, que se corresponde con la fase constructiva IX, ya que una puerta de estas dimensiones no 

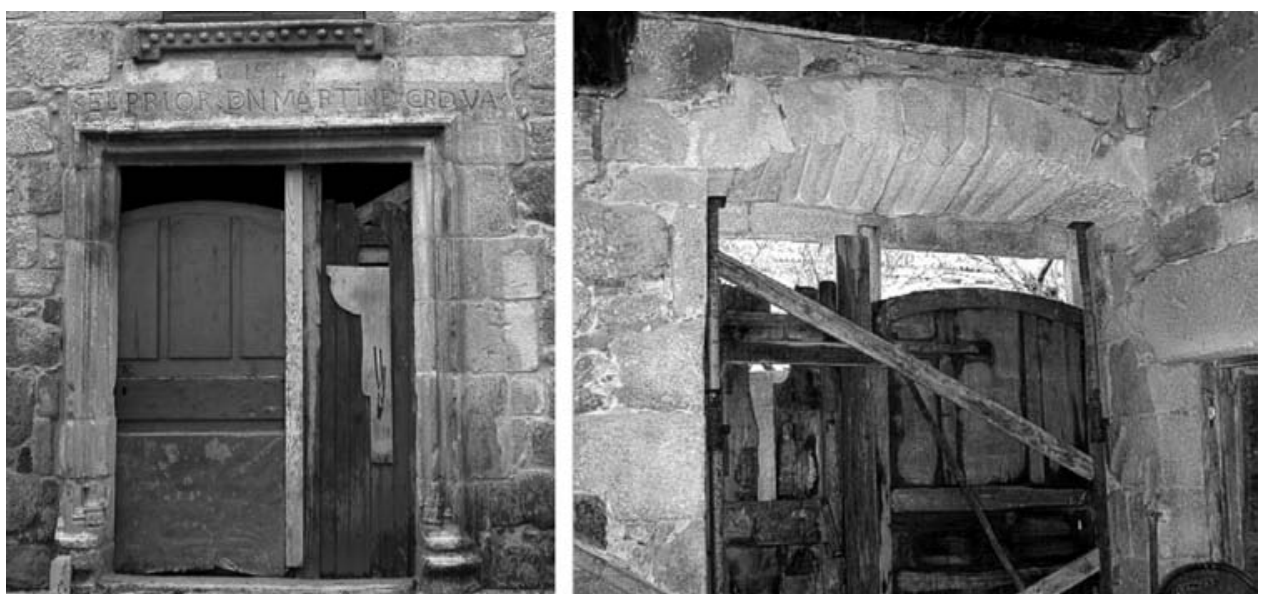

Figura 15: Interior y exterior de la puerta principal del Pazo Prioral. Se puede apreciar cómo en el arco interior las dovelas han sido recortadas y recolocadas. Al exterior se observa la reutilización de las piezas, también recortadas.

tiene cabida en ninguno de los vanos o cortes para vanos documentados en el edificio. Este dato quizás nos obliga a replantearnos la posibilidad de que el edificio que estamos estudiando no sea el Pazo Prioral y que éste se localizase donde hoy se emplaza el Palacio Episcopal. Aunque posiblemente sí cuente con alguna funcionalidad relacionada con dicho pazo. Con los datos de los que disponemos hasta el momento no podemos afirmar o desmentir esta hipótesis.

En este momento se habilitaría una nueva estancia en los sectores E y E', mediante la construcción del muro que forma su alzado N (UE173, ver figura 13). Llama la atención la puerta que se localiza en este muro en la planta baja, ya que presenta distintos agujeros para encastrar una reja. El cierre W de esta habitación no sería el que actualmente se conserva, sino que estaría más retranqueado hacia el E. Cabe la posibilidad de que se trate del lugar destinado a cárcel que se menciona en la documentación.

Se reconfiguraría también la escalera de subida a la primera planta, de la cual sólo se conserva el tramo superior en la planta alta y en la baja la estructura maciza sobre la que descansa el tramo superior de esta escalera.

Dentro de esta fase hemos incluido la reforma de la puerta situada en el alzado E de F', en la que finaliza la escalera que se construiría en esta misma fase: se ciega en parte, se corta y se reutiliza una puerta medieval de la fase III, construyendo ahora en ese mismo vano una puerta adintelada, con el dintel dovelado formado por tres piezas. Finalmente, se abriría una puerta en el alzado $\mathrm{N}$ y otra en el alzado $\mathrm{S}$ del sector D'. Como sucedía para las fases medievales, los vanos han sido claves para vincular las UE a una fase u otra, ya que todos ellos siguen una tipología muy similar. 


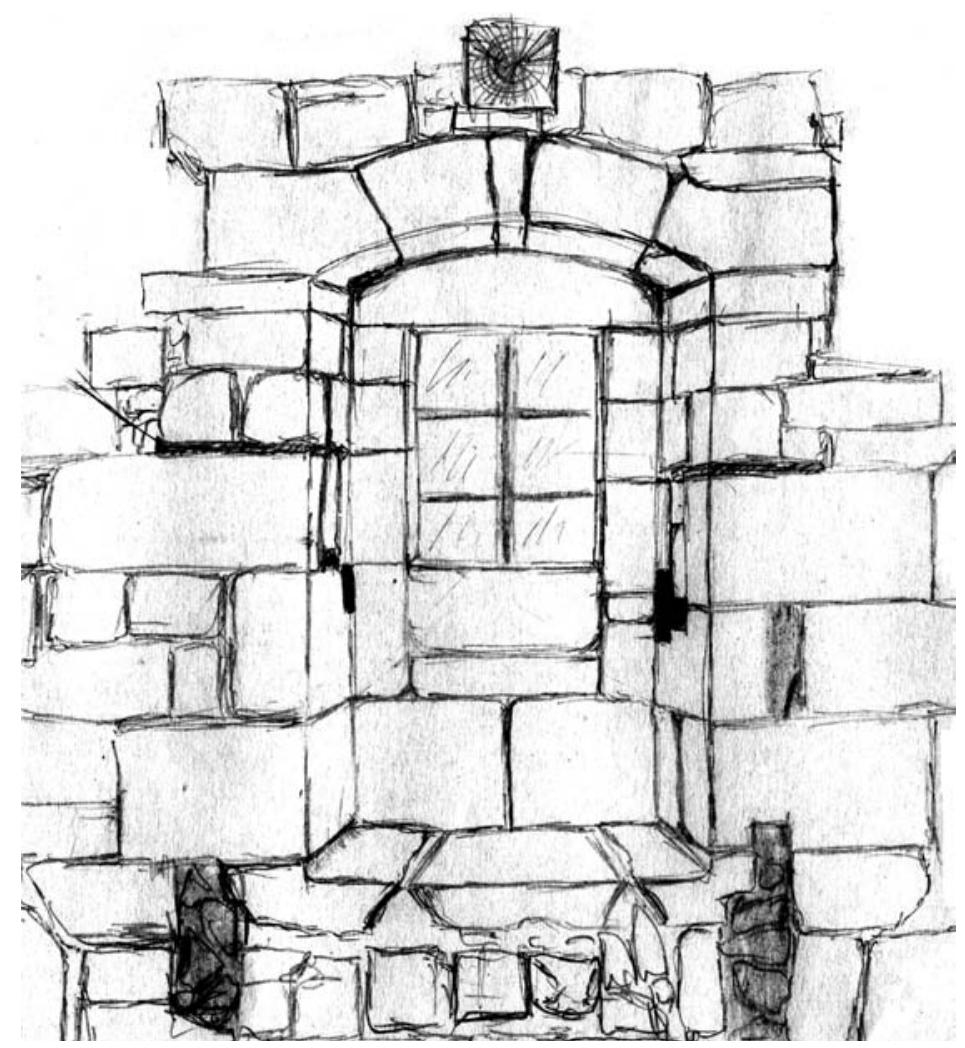

Figura 16: Croquis de uno de los vanos correspondientes a la fase VII (alzado W del sector F').

Por lo general, se trata de vanos adintelados al exterior y rematados en un arco escarzano al interior. Están ligeramente abocinados al interior y pueden presentar algún tipo de moldura o pequeño filete en las aristas de las jambas exteriores. A este tipo responden las puertas situadas en los alzado $\mathrm{S}$ y $\mathrm{N}$ de D', la puerta situada en el alzado E de F', en la que finaliza escalera, los balcones situados en el alzado W de F', las puertas situadas en los alzados $\mathrm{N}$ de $\mathrm{E}$ y E' y la puerta situada en el alzado $\mathrm{N}$ de G. Además, a este mismo tipo responde también la que es hoy puerta principal, aunque con una decoración más profusa que las anteriores. El cierre o modificación de vanos y puertas anteriores bajo un mismo estilo decorativo de gran sencillez, el repique de la decoración de las puertas medievales, unido al revestimiento de los alzados interiores, darían un tratamiento aparentemente unitario a toda la construcción, sobre todo en la zona residencial localizada en la segunda planta. Todo ello nos habla de la intencionalidad de unificar la apariencia del edificio interior y exteriormente. 

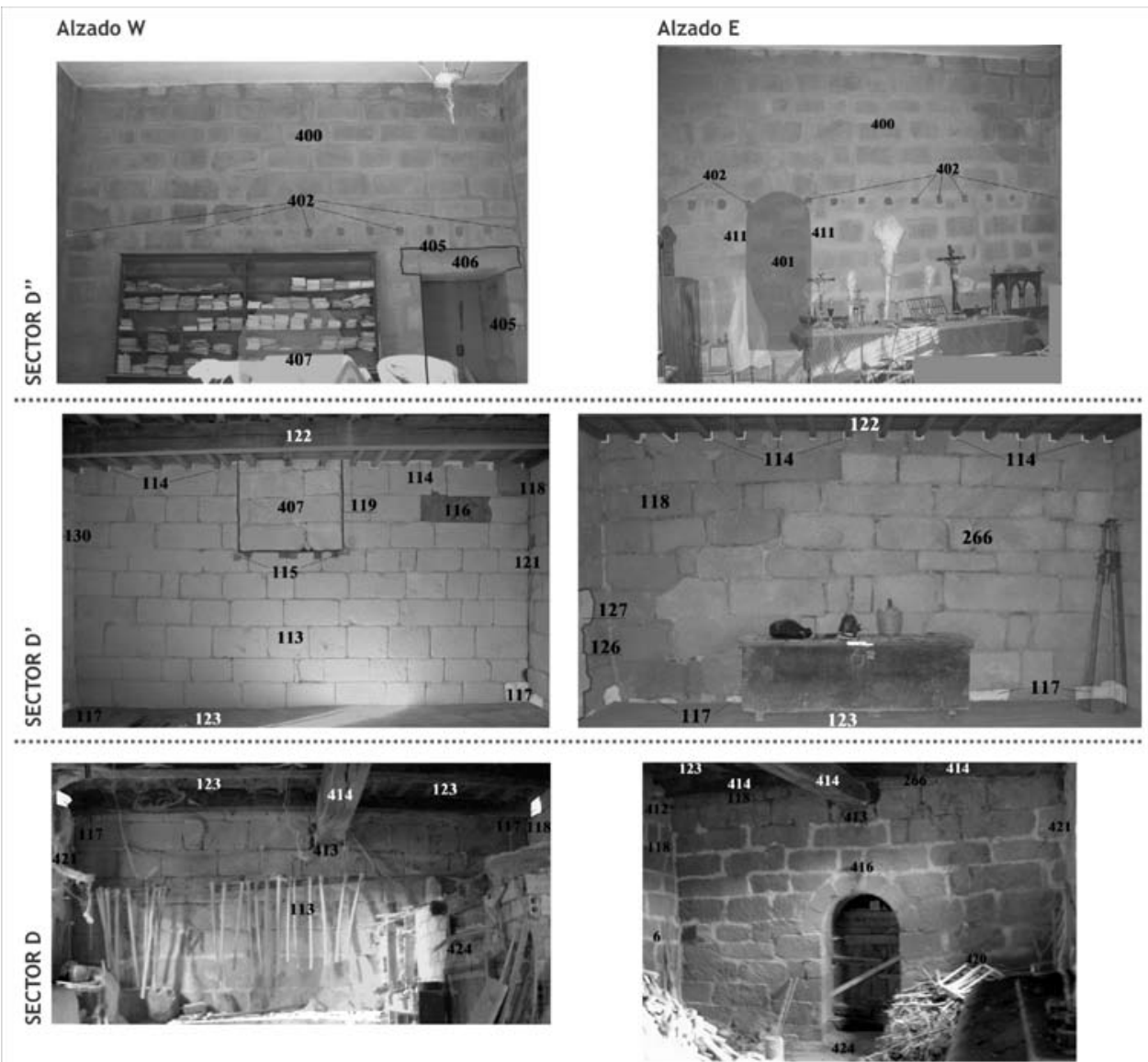

Figura 17: Diferenciación de UE en los alzados W y E de los sectores D, D' y D" (segundo cuerpo). Se puede apreciar la variación de las alturas de los vanos y los mechinales correspondientes a las líneas de suelo en diferentes fases constructivas.

También hemos incluido en esta fase la articulación en tres pisos del tercer cuerpo. En este caso, llama la atención la existencia de puertas y ventanas en los alzados de los sectores D, D' y D" situadas a distintas alturas, de hecho, todavía no hemos conseguido establecer cuál sería la división interna de estos espacios en época medieval, sobre todo porque al haberse eliminado parte de la estructura originaria de cada edificio, hemos perdido su configuración espacial. Parece claro, sin embargo, que en la fase VII la división debía ser la misma que la actual, ya que, siguiendo esta estructuración se construyen las puertas de D' que acabamos de indicar. La viguería y los suelos actuales están cortando los anteriores vanos medievales. 
Al mismo tiempo, el suelo actual de E', F' y G', así como las vigas sobre ménsulas decoradas que soportaban la cubierta anterior, serían también de este momento. En la figura 13, se puede apreciar que la línea de mechinales UE198, que habíamos identificado con el suelo del corredor adosado a la fachada $\mathrm{W}$ medieval de la fase IV, no se corresponde con el actual suelo de los sectores G' y F'. Los mechinales situados sobre los anteriores en los que se encastra la viguería actual y el cierre de los mechinales UE198, pertenecerían entonces a la fase VII.

\section{Reconstrucciones y reestructuraciones en época contemporánea.}
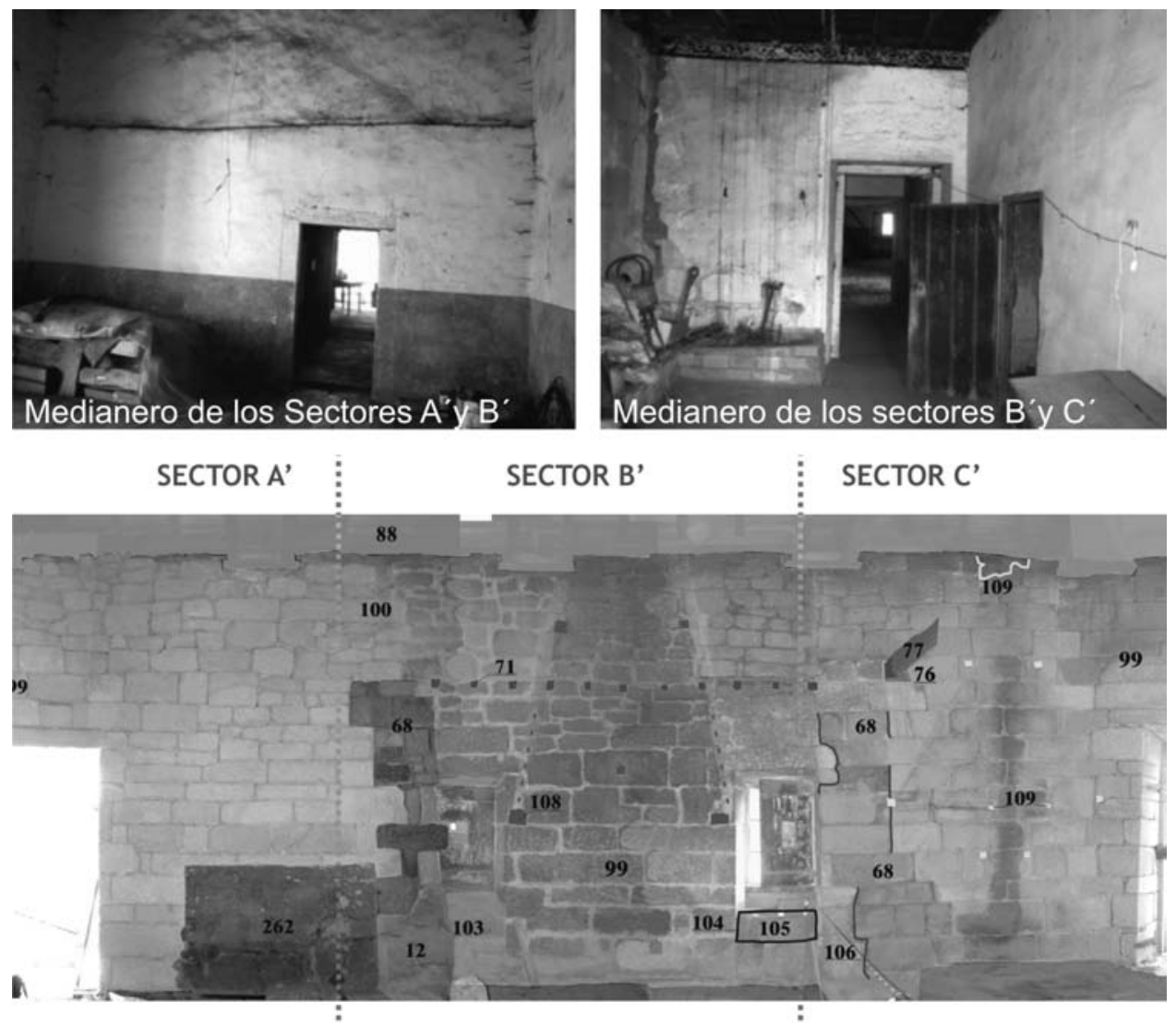

Figura 18: Las imágenes superiores muestras los muros medianeros que dividían los sectores A', B' y C' (fotografías proporcionadas por los arquitectos Recuna y Mendizábal S.C.).

La imagen inferior, obtenida una vez eliminados estos muros, muestra las huellas dejadas en el alzado E de estos sectores: los cortes del alzado para encastrar los muros medianeros (UE106), los restos de estos muros (UE068) o las lareiras allí emplazadas en distintas fases (UE108, 109). 
Este nuevo período constructivo comienza con las reformas realizadas en el edificio con posterioridad a la Desamortización de Mendizábal en julio de 1837. En el año 1850 el Palacio se encontraba muy arruinado, reparándose puntualmente entre los años 1830 y 1850 , hasta que se acomete una importante reforma fechada en el año 1853 , como indica el epígrafe que se localiza en su fachada $\mathrm{W}$ sobre la ventana situada encima de la puerta principal.

\section{Fase constructiva VIII}

En esta etapa se produce una reconfiguración de la totalidad del interior del edificio, donde se construyen medianeras que habilitan nuevos espacios (sectores A, A', B, B', C y C' en el primer cuerpo y sector G y G' en el tercer cuerpo). Se reconstruye la esquina $\mathrm{N}$ de la fachada $\mathrm{W}$ (UE159), el coronamiento de la primera planta (UE253), la planta alta de la fachada E y se construye la actual escalera.

En el caso de los muros que dividen el espacio de la planta baja, el muro corrido que separa los sectores C y B podría levantarse sobre una cimentación de sillería anterior, que se ha documentado durante el control arqueológico. Estos muros, además de habilitar una nueva división espacial, contribuyen a la sujeción de los alzados E y W de este cuerpo.

Por otro lado, la planta alta de la fachada $\mathrm{E}$ ha sido totalmente modificada como consecuencia de los problemas estructurales que ha tenido el edificio en esta zona desde momentos muy tempranos, y que ya se han comentado. Así, se reconstruye toda esta fachada en altura y, al mismo tiempo, se construyen dos muros medianeros realizados en sillería en la planta superior que configuran los sectores A', B' y C' y que se montan sobre los muros medianeros de mampostería de la planta baja.

Mientras los muros de la planta baja están adosados a los paramentos medievales, los de la alta en su extremo E se construyen con el muro que se levanta en esta fase y en su extremo $\mathrm{W}$, donde coinciden con un muro preexistente, éste se corta para encastrarlos. Ello obliga a cegar la puerta adintelada que se había reformado en la fase anterior sobre una previa medieval, en la zona donde finalizaba la escalera.

En esta época el edificio se destina a Rectoral. Los muros medianeros de la planta superior permiten habilitar distintas estancias que se emplean ahora con un uso habitacional.

La actual escalera, situada en los sectores F y F', es de dos tramos en escuadra, con un descanso entre el primer y el segundo tramo. Presenta una planta en L cerrada. El tramo inferior está adosado al alzado $\mathrm{W}$ del sector F, pero se encuentra separado de éste en la parte baja para ir aproximándose a la fachada a medida que asciende, hasta encontrarse con ella a la altura del descanso. Así, entre la escalera y la fachada, se forma una especie de cuña, cuyo frente $\mathrm{N}$ está realizado con un aparejo de sillería que sigue las mismas hiladas que la jamba $\mathrm{S}$ de la puerta principal, desde la que 
parte, mientras que para su relleno se emplean mampuestos y piezas reutilizadas. El siguiente tramo se construye ya paralelo al alzado $\mathrm{S}$ de los sectores $\mathrm{F}$ y F', creemos que en este caso se estaría aprovechando la estructura de una escalera perteneciente a la fase anterior, así como parte de la bóveda que daba acceso al sector A en la fase IV.

Toda la estructura se construye mediante una serie de bloques que se van adosando entre sí, probablemente como consecuencia de estar montando la nueva estructura sobre dos precedentes (escalera y bóveda). Debajo del descanso se construye un paso cubierto con una bóveda en mitra, que permite la comunicación interior entre las dos entradas de la fachada $\mathrm{W}$ y los dos espacios generados en este sector una vez finalizada la escalera.

A esta fase correspondería también la apertura de seis ventanas con antepecho adinteladas al exterior y abocinadas al interior en los alzados $\mathrm{W}$ y E del sector A'. Se sitúan en dos alturas. La necesidad de abrir nuevas ventanas en esta zona viene motivada porque aquí se construye ahora una estructura de madera creando una tercera

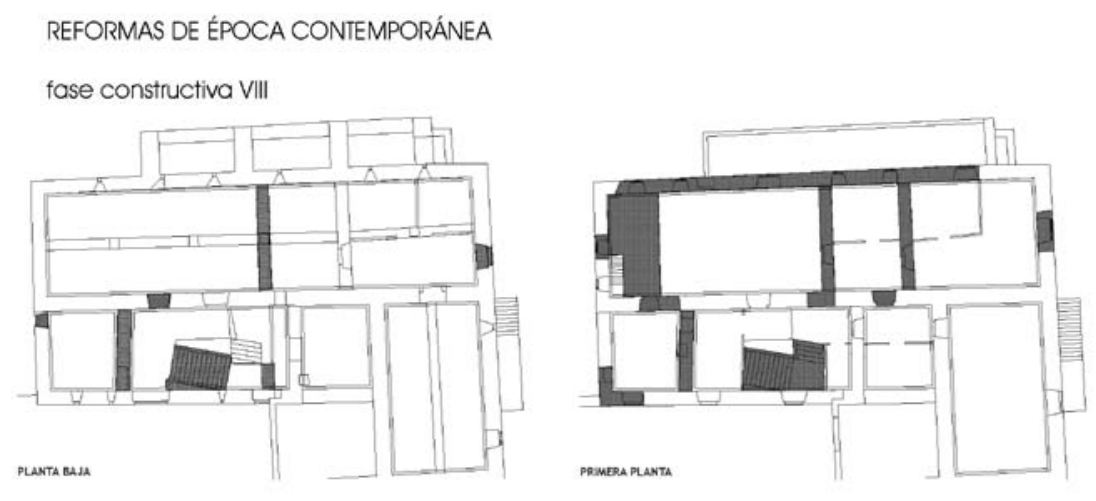

fase constructiva XI
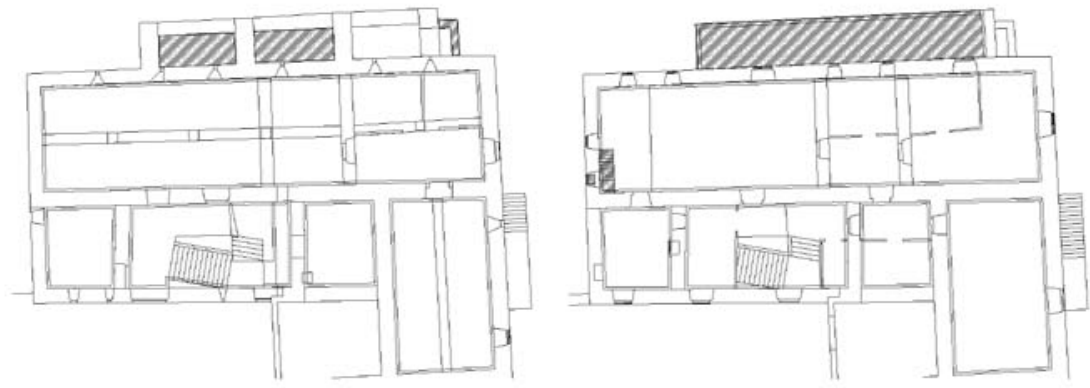

Figura 19: Planta del edificio, en la que se han representado las fases contemporáneas documentadas. 
altura en parte del sector A', la cual era de mayores dimensiones que la que actualmente se conserva, llegando en la fase VIII casi hasta la puerta medieval del alzado W rematada con un arco de medio punto. A ella se accedía por una escalera que estaba adosada y encastrada en el alzado $\mathrm{W}$ de este sector. De la estructura restante y la escalera original únicamente conservamos los mechinales de las vigas y los agujeros y rozas en los que se encajaban los peldaños y el pasamanos de madera.

Fases constructivas $I X, X$ y XI

Hemos incluido en estas etapas las distintas reformas realizadas a lo largo del s. XX y principios del s. XXI.

\section{Fase IX}

Esta fase corresponde a la construcción del Palacio Episcopal entre los años 1902-1906, adosado a la fachada W de D, D' y D".

Se ciegan las ventanas $\mathrm{N}$ y E del sector D" con mampostería al exterior y sillería al interior. En uno de los mampuestos de la ventana $\mathrm{E}$ aparece la fecha de 1905, la cual permite datar este cierre. Se abren en este mismo sector una puerta adintelada en el alzado W, que comunica directamente con el Palacio Episcopal y una puerta-balcón en su alzado S. A esta fase correspondería también la escalera exterior desde la que se accede al sector D', que obliga a cegar una puerta medieval en el sector D, y a abrir otro nuevo acceso por esta zona que salve la escalera.

También se adelante la fachada W de los sectores E y E', mediante un muro de mampostería irregular a hueso, que contiene dos pequeños vanos de ventilación en la parte alta del sector E, sobre los que luego se disponen unos troncos, a modo de vigas, para ampliar el suelo del sector E'.

Fase $X$

Se construye el actual garaje (sector $\mathrm{H}$ ), que obliga a cegar la puerta principal por la que se accedía al segundo cuerpo (situada en el alzado $\mathrm{N}$ del sector $\mathrm{D}$ ) y parte de la jamba de la puerta adintelada localizada en la fachada W del Pazo.

Además se lleva a cabo alguna reforma en el interior del edificio, como la construcción de un fallado o de otros muros medianeros realizados con materiales perecederos, como los que se localizaban en el sector F'.

\section{Fase XI}

Hemos incluido en esta fase aquellos elementos que presentaban un mismo aparejo como los muros en talud situados entre los contrafuertes de la fachada $\mathrm{E}$ y la estructura que cierra la parte baja de la letrina del contrafuerte S. Además, creemos que dentro de esta fase se realizarían otras reestructuraciones de las habitaciones de los sectores B' y C'. Pertenece igualmente a esta fase la construcción del gran balcón de hormigón que se dispone sobre los contrafuertes de la fachada E. Finalmente, se acortaría la estructura de madera que formaba el altillo en el sector A' y 
se abriría una nueva escalera de subida a la misma en su esquina NW. Hemos datado esta fase en los años centrales del s. XX, concretamente sabemos que el cierre de la letrina se lleva a cabo en los años 60.

\section{Fases constructivas XII y XIII.}

A la fase XII se ha vinculado la reforma de la cubierta del primer y tercer cuerpo del edificio en el año 2003, y la fase XIII la restauración arquitectónica desarrollada en el año 2005, en la que se limpiaron y rejuntaron las fachadas, se limpiaron los paramentos interiores y se eliminaron algunos muros medianeros.

\section{SOBRE LAS MARCAS EPIGRÁFICAS DOCUMENTADAS}

Esta última fase de restauración ha permitido documentar una serie de marcas epigráficas de distinto tipo. Dentro del estudio realizado no se planteaba como objetivo el análisis de dichas marcas, pero recogemos un breve apunte sobre las mismas porque resultan de gran interés y creemos que deberían estudiarse de forma más exhaustiva en fases posteriores.

Estas marcas son de varios tipos: marcas de cantero, epígrafes, graffitis y juegos.

- Marcas de cantero: existe una evidente asociación de algunas marcas a cada una de las fases constructivas medievales, siendo indudable la diferencia entre las marcas de la fase I y las de las distintas etapas de las fases II y III.

Con la única excepción de una marca en forma de cruz, una de las más comunes de época medieval, que se repite en las tres fases, y de la "V" que localizamos en las fases I y II, las demás documentadas son distintas en cada fase.

En la fase I aparecen representadas: el báculo, una figura en forma de triángulo y la "V", como elementos más representativos, además de la cruz (figura 20). En la fase II hemos documentado: la cruz, la "V" y la "L"; aunque en esta etapa las marcas de cantero son más escasas que en las otras dos. En la fase III la más común es la "L", que aparece en mayor número que las demás, después estaría la cruz y una "Z" o "S" muy abierta. Además, estas marcas aparecen también en algunos sillares reutilizados en fases posteriores, como por ejemplo en los cierres de vanos.

Si se llevara a cabo un estudio epigráfico del edificio, habría que ponerlo en relación con la Colegiata ya que en ambos edificios se documentan las mismas marcas.

- Epígrafes: se han documentado hasta la fecha cuatro epígrafes, a tres de ellos, fechados en 1594, 1853 y 1905, ya se ha hecho mención anteriormente, el tercero se puede apreciar en la figura 20. 


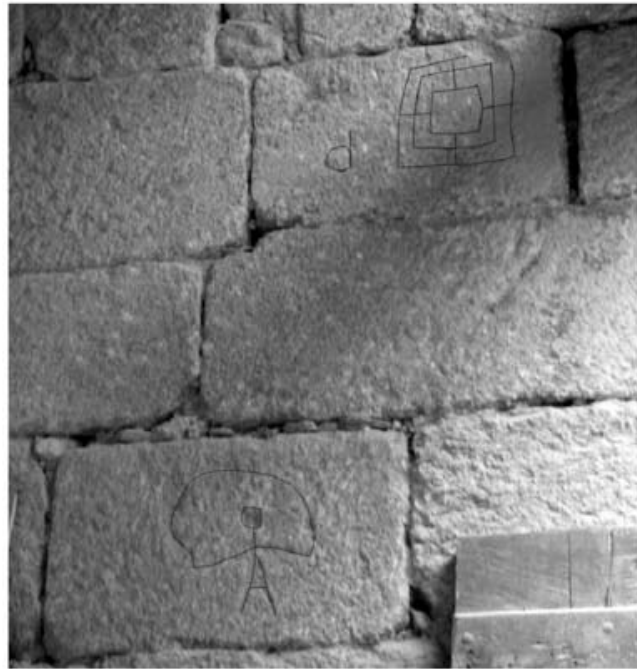

Grafittis realizados en la fachada W de la Fase III

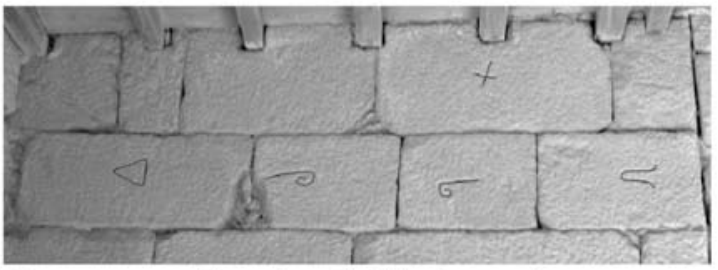

Algunas marcas de cantero identificadas en el muro perteneciente a la Fase I

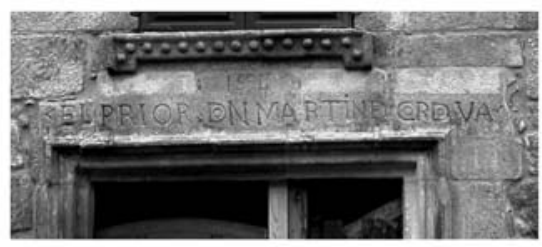

Epigrafe en la puerta principal de la fachada W

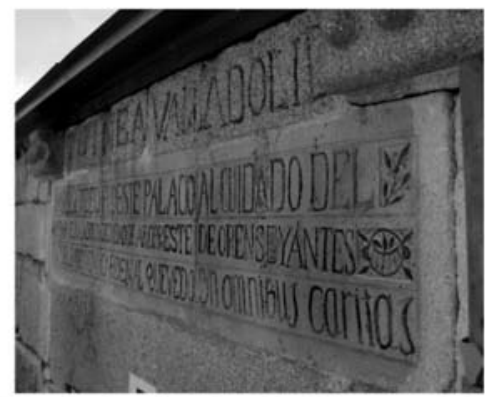

Epigrafe situado sobre el balcón central de la fachada $W$

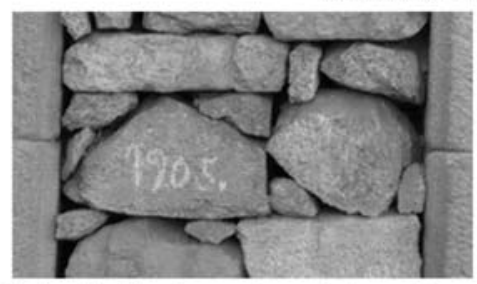

Epigrafe situado en cierre de la ventana E de D", en el exterior

Figura 20. Marcas de cantero, grafittis y epígrafes documentados en el Pazo Prioral.

- Graffitis y juegos: se han documentado también algunos graffitis y un juego.

En la fachada W medieval se han documentado, además de varias marcas de cantero, dos graffitis: uno representa una figura humana, posiblemente femenina, con los brazos abiertos sosteniendo un elemento curvo sobre su cabeza. Está realizada con un instrumento metálico, los trazos son finos, las extremidades y el elemento curvo son una simple línea, la cabeza, carente de rasgos, está formada por una cazoleta y para lo que parece una falda también se hace un rebaje como en la cabeza. Es muy esquemática, pero recuerda a la figura humana representada en uno de los bajorrelieves que se conservan en la fachada principal de Santa Eulalia de Bóveda (Lugo), en el cual se representa una figura, que algunos autores identifican como masculina, sosteniendo sobre la cabeza una guirnalda de flores. 
Dos sillares por encima de este graffiti se localiza otro que representa un tablero de Alquerque de IX o "juego de molino" (según la denominación recogida por COSTAS e HIDALGO 1998: 99-104): se trata de tres cuadrados concéntricos con los centros de sus lados unidos por trazos rectos, como se aprecia en la figura 20. Está realizado con un instrumento metálico, los trazos de las líneas son muy finos y la parte superior derecha está cortada. Según estos mismos autores, esta sería la forma más simple de este tablero y está documentado "[...] en la iglesia románica de Gomariz (Leiro, Ourense) sobre una bancada del exterior de la misma; en una bancada del interior de la Catedral de Ourense y en el interior de la Catedral de Tui (Pontevedra), también se encuentra en un sillar de la fábrica del muro del Museo Arqueológico de Ourense que da a la calle Hernán Cortés." (ídem: 102), es decir, en un entorno bastante próximo a Xunqueira.

Es evidente, que en el caso de Xunqueira, se trata de una representación del tablero, ya que por su posición no se podría llevar a cabo el juego.

Resulta interesante que ambos graffitis se encuentran en una posición importante dentro del edificio, en una de las zonas de entrada principales de la primera planta. Si a ello unimos que las dovelas del arco que remata la puerta también presentan signos epigráficos que no parecen marcas de cantero, todo apunta de alguna manera al carácter simbólico de estos grabados y a la intención de "marcar" este acceso.

Se documenta en el Pazo otro tablero de Alquerque IX más complejo que el anterior, situado en el sillar inferior del alzado $\mathrm{S}$ del pilar del sector E. Únicamente podemos apreciar la mitad superior del mismo, ya que el sillar está semienterrado.

En este caso los surcos son más profundos y anchos. Es una figura formada por tres cuadrados concéntricos y tiene una pequeña cazoleta en cada uno de sus vértices y centros de los lados de los cuadrados. Además de estar unidos los centros de los lados por una línea recta, lo están también sus vértices.

Según nos comentan los autores, existen ejemplos en los que los cuadrados tienen los vértices y centros de los lados unidos por una línea recta, pero carecen de cazoletas y se localizan en el Castro de Xián (Vincio, Gondomar) y en Monte Lobeira (Vilanova de Arousa, Pontevedra). También han documentado otro tablero situado en un sillar reutilizado en una pared de la ermita de Santa María de Petín (Barco de Valdeorras, Ourense) (ídem: 102). Pero no se documenta ningún caso en el que se den ambas variantes del tablero sencillo de forma conjunta (con cazoletas en vértices y centros de los lados y uniendo con una línea recta estos puntos), como en el caso de Xunqueira.

Evidentemente, para visualizar por completo el tablero habría que excavar el suelo de la estancia. Creemos que en este caso sí podría tratarse realmente de un tablero que se emplearía como juego (y no su simbolización como en el graffiti), 
pero por su posición en vertical posiblemente se esté reutilizando un sillar medieval en la fase IV para la construcción de este pilar.

Para Costas e Hidalgo,'Este tipo de juego tiene sus antecedentes en época romana." Datándose algunos de los ejemplares gallegos en esta época, aunque se atribuye la mayoría a época histórica, fundamentalmente pleno y bajomedieval (en las mismas dataciones en las que nos movemos en la fase III del Pazo Prioral en torno al s. XII).

- Otras: además de las marcas anteriores, se han documentado otro tipo de grabados que no podemos vincular a ninguno de los tipos anteriores. Algunos de ellos pueden tratarse de "marcas de posición", escasamente estudiadas en Galicia, o de otro tipo de signos.

En algunos de los sillares que constituyen los pilares de los sectores A, B, C y E se documentan algunas flechas, aunque son diferentes las localizadas en los pilares de los tres primeros sectores que en el del sector E. Creemos que este tipo de signo se correspondería con las "marcas de posición", las cuales posiblemente indiquen la posición que debe adoptar el sillar con respecto a las trazas de la construcción.

\section{BIBLIOGRAFÍA}

Fuentes Consultadas

CANÓNIGOS DE XUNQUEIRA DE AMBÍA, Historia de este priorato y señorío, año 1671.Caja 49. AHDO.

CASAS DE LA PREBENDAS. 1849. Xunqueira de Ambía. Caja 49. AHDO.

CATASTRO DE ENSENADA, Xunqueira de Ambía. Real de Eclesiásticos. Libro 2113. Año 1752. AHPO.

CATASTRO DE ENSENADA. Xunqueira de Ambía. Interrogatorio. Libro 2110. Año 1752. AHPO.

CATASTRO DE ENSENADA. Xunqueira de Ambía. Estados D-H. Libro 4183. Año 1752. AHPO.

CONSTITUZIONES de la INSIGNE YGLESIA COLEGIATA DE STA Ma DE JUNQUERA DE AMBÍA, 1634 Clero. Caja 10186, nº 223. AHPO.

CUENTAS DE FÁBRICA 1740-1840. Xunqueira de Ambía, Caja 17. AHDO.

CUENTAS DE FÁBRICA 1625-1840. Xunqueira de Ambía, Caja 27. AHDO.

DOCUMENTOS. AHPO. Sección Clero. Xunqueira de Ambía. Caja 10.185.

FABRICA MENOR. Xunqueira de Ambía, Caja 49. AHDO.

INFORMACIÓN TESTIFICAL hecha en virtud de R. Cédula de Carlos V, de 9 de septiembre de 1541. AHPO. Clero. Xunqueira de Ambía. Libro 766.

INVENTARIOS DE 1707-1940. Xunqueira de Ambía, Caja 49. AHDO. 
MARTÍN DE CÓRDOBA, Libro Tumbo, ano 1594, AHPO. Sección Clero. Xunqueira de Ambía. Libro 755.

RENTAS DE LA TULLA PRIORAL. Xunqueira de Ambía, Caja 30. AHDO.

Bibliografía consultada

AMADO ROLÁN, N., Informe Histórico-Arqueolóxico sobre o Pazo Prioral da Colexiata de Sta. M. ${ }^{a}$ A Real de Xunqueira de Ambía, informe inédito 2005.

BARROS GUEDE, J., Historia y Arte de Xunqueira de Ambía, A Coruña 2004.

BAS, B., As construcións populares: Un tema de etnografía en Galicia, Cuadernos do Seminario de Sargadelos, 44, A Coruña 2002.

BLANCO ROTEA, R. - GARCÍA RODRÍGUEZ, S., Lectura de alzados del Pazo Prioral de la Colegiata de Santa María de Xunqueira de Ambía (Ourense), Laboratorio de Patrimonio, Paleoambiente e Paisaxe (IIT, USC), informe inédito 2006.

CAAMAÑO SUÁREZ, M., As construccións adxectivas, Cuadernos do Museo do Pobo Galego, Santiago de Compostela 1999.

COSTAS GOBERNA, F. J. - HIDALGO CUÑARRO, J. M., Reflexiones sobre el Arte Rupestre Prehistórico de Galicia. Vigo 1998.

CRESPO POZO, J. S., "El priorato de Santa María la Real de Junquera de Ambía”, Revista Estudios, (1964-1967).

FERNÁNDEZ ALONSO, B., "Junquera de Ambía”, Comisión Provincial de Monumentos de Orense, 2, 43-44 (1905), 329-33, 345-50.

FERRO COUSELO, J., "Don Alonso de Piña, fundador de la villa de Junquera de Ambía”, La Región, (1970), Ourense.

GAlLEGO DOMÍNGUEZ, O., "Hospitales de la Provincia de Orense”, Boletín Auriense, 6 (1976), 207-63.

GONZÁlEZ GARCÍA, M. A., "Don Alonso de Piña, Chantre de Ourense, Prior de Xunqueira de Ambía, mecenas y hombre de gobierno", Escritos dedicados a José María Fernández Catón. Centro de Estudios e Investigación "San Isidoro”, León 2004, 571-95.

GONZÁLEZ GARCÍA, M. A., El retablo mayor de la Colegiata se Xunqueira de Ambía (Ourense), Grupo Francisco de Moure, Zamora 2002.

PLACER, FR. G., "Junquera de Ambía. Datos para la historia de la villa y su colegiata", Comisión Provincial de Monumentos de Orense, 11-240 (1938a), 417-30.

PLACER, FR. G., "Junquera de Ambía. Datos para la historia de la villa y su colegiata", Comisión Provincial de Monumentos de Orense, 11-241 (1938b), 440-50.

PLACER, FR. G., "Junquera de Ambía. Datos para la historia de la villa y su colegiata", Comisión Provincial de Monumentos de Orense, 11-242 (1938c), 479-88.

VÁZQUEZ NÚÑEZ, A., "La ex-colegiata de Junquera de Ambía", Boletín de la Comisión de Monumentos de Orense, 1-17 (1900), 297-301. 